\title{
La ciudad com-fusa: mercado y producción de la estructura urbana en las grandes metrópolis latinoamericanas
}

Pedro Abramo. Instituto de Investigación y Planificación Urbana y Regional, Universidad Federal de Río de Janeiro, Río de Janeiro, Brasil.

RESUMEN | Con la crisis del fordismo urbano, el mercado inmobiliario ha resurgido como una fuerza determinante del proceso de coordinación social del uso del suelo y la producción de estructura intraurbana. Es el retorno de la "mano invisible" del mercado. En este artículo se analiza la relación entre la producción de estructura urbana y el funcionamiento del mercado inmobiliario en América Latina, tanto en su versión formal como en la informal. La hipótesis de trabajo es que las ciudades latinoamericanas, comparadas con los dos modelos tradicionales (la urbe compacta mediterránea, y la difusa anglosajona), muestran una estructura urbana particular. En ellas, el funcionamiento de los mercados del suelo produce simultáneamente una estructura urbana compacta y difusa. Es a esta estructura, característica de las grandes urbes latinoamericanas, que llamamos ciudad "com-fusa".

PALABRAS CLAVE | estructura urbana, mercado de suelo, economía informal.

\begin{abstract}
With the crisis of urban Fordism, the real estate market has reemerged as a determining force in the social coordination process of land use and in the production of intraurban structure. It has been the return of the "invisible hand" of the market. This paperpresents an analysis of the relationship between the production of urban structure and the functioning modes offormal and informal land markets in Latin America. It proposes the hypothesis that, compared to the two traditional models (compact Mediterranean cities and the Anglo-Saxon diffused cities), Latin American cities exhibit a particular urban structure. In these cities, the functioning of land markets produces simultaneously a compact and a diffused urban structure. This urban structure, characteristic of large Latin American cities, we designate as the "Com-Fused" City.
\end{abstract}

KEY WORDS | urban structure, land market, informal economy.

Recibido el 30 de junio de 2010, aprobado el 23 de junio de 2011

E-mail: abramo@ippur.ufrj.br 


\section{Introducción}

A principios de los años ochenta comenzó a hacerse patente en los países más desarrollados la crisis del fordismo urbano, un proceso que junto con el surgimiento de lo que algunos autores llaman la "nueva política urbana", puede ser considerado como el marco formal de institucionalización de la ciudad neoliberal (Moulaert, Rodríguez \& Swyngedouw, 2003). Otros procesos acompañan este movimiento, en particular la crítica al racionalismo constructivista del urbanismo moderno y la difusión del discurso del multiculturalismo urbano y de la fragmentación étnicocultural y religiosa en las grandes ciudades (Taylor, 2002). En este texto se aborda un rasgo esencial de la construcción estructural de la ciudad neoliberal: el retorno del mercado como elemento determinante de la producción urbana posfordista.

La crisis del fordismo urbano se manifiesta, sobre todo, a través de dos ejes de cambio: por una parte, la tendencia hacia la flexibilización urbana por sobre el urbanismo modernista y regulador; y por otra, la caída en el financiamiento estatal de la materialidad urbana (vivienda, equipamientos e infraestructura) y de algunos servicios urbanos colectivos. En ambos casos, el mercado resurge como mecanismo principal de coordinación de la producción de la ciudad, ya sea a través de la privatización de las empresas públicas o por la hegemonía del capital privado en la producción de las materialidades residenciales y comerciales urbanas. Este predominio del mercado como mecanismo de coordinación de las decisiones de uso del suelo constituye un rasgo característico de la ciudad neoliberal, en contraste con el periodo del fordismo urbano, cuando el papel del mercado en la producción de las materialidades urbanas estaba fuertemente mediado por el Estado a través de la definición tanto de las reglas de uso del suelo como de las características de tales materialidades. La crisis del fordismo urbano implica, por tanto, el "retorno del mercado" como elemento determinante en la producción de la ciudad neoliberal.

En los países latinoamericanos, la producción de las ciudades modernas resulta del funcionamiento de dos lógicas de coordinación social: la del mercado y la del Estado; pero también de una tercera: la lógica de la necesidad. Esta última movió - y continúa haciéndolo - un conjunto de acciones individuales y colectivas que promovieron la producción de las "ciudades populares", con su habitual ciclo ocupación/autoconstrucción/autourbanización y, finalmente, consolidación de los asentamientos populares informales (API). Recientemente ha surgido una nueva variante de producción de la ciudad popular que articula la lógica del mercado con la de la necesidad, y se manifiesta socialmente como el "mercado informal de suelo" (Abramo, 2003a).

La hipótesis de trabajo que aquí se propone reafirma que el mercado, al ser el principal y hegemónico mecanismo de coordinación de las decisiones de uso del suelo, produce una estructura o forma de ciudad particular y característica de América Latina: una estructura "híbrida" desde el punto de vista de su morfología de usos del suelo, vis à vis los modelos tradicionales de la ciudad moderna. Esta última, la ciudad moderna, tiene dos formas paradigmáticas, en términos materiales, de 
conformación estructural de su ambiente construido. La primera está identificada como el "modelo mediterráneo" o "continental" y su estructura urbana se configura como una ciudad "compacta", donde el uso del suelo es intensivo. La segunda responde al "modelo anglosajón" y su manifestación espacial es la ciudad "difusa", con un uso del suelo fuertemente extensivo y una baja densidad predial (por lote) y residencial (por vivienda).

La hipótesis que se desarrollará a lo largo de este capítulo es la siguiente: el funcionamiento del mercado del suelo en las grandes ciudades latinoamericanas promueve, de forma simultánea, una estructura de ciudad compacta y difusa. Ello apunta a que las urbes latinoamericanas tienen una estructura generada por un uso del suelo que se compacta y se difunde, o se difunde y se compacta. En este sentido, la producción de la estructura urbana en América Latina concilia las formas compacta y difusa de uso del suelo y, de esta forma, promueve una forma particular: la ciudad "com-fusa".

Lo que se pretende demostrar en este trabajo es que, en América Latina, tanto el mercado formal del suelo y de las edificaciones como el mercado informal producen, simultáneamente y por razones particulares y vinculadas a sus propias lógicas de funcionamiento y de reproducción de los capitales, una ciudad com-fusa. En síntesis, el funcionamiento del mercado formal produce un tipo de ciudad compacta y difusa, así como el funcionamiento del mercado informal del suelo también produce una ciudad popular o informal compacta y difusa.

Además, se subraya que la producción y la reproducción de la forma com-fusa de las grandes ciudades de la región se alimenta de un doble proceso de retroalimentación de los mecanismos de promoción de la forma compacta y difusa del uso del suelo urbano, uno de naturaleza formal y otro con características informales. La producción de las materialidades urbanas y, sobre todo, de los mecanismos promotores del uso del suelo en el marco de la ciudad neoliberal, conduce a una lógica interna de funcionamiento del mercado formal y del informal que promueve un círculo perverso, donde la compactación alimenta la difusión y esta fomenta la compactación. En otras palabras, el retorno de la "mano inexorable" del mercado del suelo produce y potencia la estructura espacial de una ciudad com-fusa. Como es posible imaginar, esta estructura promueve demandas de equipamientos y servicios con señalizaciones espaciales diversas, y es un factor que dificulta la elaboración de políticas urbanas más equitativas en términos socioespaciales.

\section{Producción y reproducción de la ciudad popular informal: el mercado informal de suelo urbano}

La ciudad popular o informal no es un fenómeno reciente en América Latina: es posible identificar procesos de producción de territorios populares urbanos al margen de las reglas y de las normas oficiales, activos desde los tiempos de la Colonia en prácticamente todos los países de colonización portuguesa y española. La urbanización acelerada del siglo XX tuvo un papel determinante en la amplificación de ese 
proceso de producción de ciudades populares informales. Grosso modo, en la mayor parte de los países de la región, la producción de la ciudad popular está vinculada directamente a la configuración de estructuras de provisión de vivienda y de equipamientos y servicios urbanos truncados (Vetter \& Massena, 1981), característicos de un régimen de acumulación fordista excluyente (Coriat \& Sabóia, 1989, pp. 3-45) o periférico (Lipietz, 1991). La urbanización fordista acelerada y excluyente en América Latina promovió un Estado de bienestar urbano que atendía particularmente a una porción limitada de la población de las ciudades. La estructura social extremadamente estratificada y con grandes diferencias de acceso a la riqueza (concentración de la renta) fue base para el surgimiento de acciones urbanas colectivas o individuales de ocupación de suelo (organizadas y/o espontáneas), movidas por la lógica de la necesidad de acceso a la vida urbana (Abramo, 2005b); o, en términos de Agamben (2004, p. 130), se trataría de un movimiento de reafirmación de la vida en relación al derecho, que no incorporaba la vida en el derecho.

La lógica de la necesidad impulsó el proceso de ocupación popular de tierras urbanas al inicio del siglo XX, modalidad que a partir de la urbanización acelerada de los años cincuenta se transformó en la principal forma de acceso de los pobres al suelo urbano en muchos países latinoamericanos. En algunas regiones, donde el Estado de bienestar fordista excluyente promovió la producción estatal de vivienda, se ha dado un patrón de provisión de suelo urbano popular con dos vectores: la ocupación popular, y la producción de vivienda en conjuntos habitacionales o lotes urbanizados (Duhau, 2001). No obstante, la fragilidad de los sistemas de provisión pública en la mayor parte de los países de la región y el aumento de la urbanización dieron pie, paulatinamente, a la lógica de la necesidad y a su acción concreta; esto es, la ocupación popular del suelo urbano como forma dominante de acceso a la vivienda por parte de los pobres.

La crisis de los años ochenta y de los sistemas nacionales de provisión habitacional en prácticamente todos los países latinoamericanos tuvo dos grandes consecuencias. La primera fue un incremento del ciclo de ocupación y, particularmente, su esparcimiento en algunos países, donde este fenómeno no estaba muy presente, como Uruguay y Paraguay. La segunda consecuencia de la crisis fue la consolidación y la potenciación de un mercado informal de tierras urbanas. Este mercado informal popular existía en muchos países desde el inicio del siglo XX, ya fuera en forma de locación en viviendas colectivas - conventillos, cortijos, corralones, entre otras denominaciones - compartidas por varias familias pobres u otras formas precarias de vivienda, o en la mercantilización ilegal de tierras periurbanas. Esta última, el mercado informal de suelo, ha sido a partir de los años cincuenta la forma dominante de acceso a la tierra urbana en algunos países latinoamericanos. El caso mexicano es un ejemplo concreto de predominio del mercado informal a partir de la privatización individualizada (venta de lotes individuales) de las tierras colectivas ejidales rurales (Azuela, 1989). Otro caso conocido es el de Bogotá, donde prácticamente toda la ciudad popular tiene su origen en la venta informal de suelo urba- 
no ("urbanización pirata"). Es decir, el acceso de los sectores populares a un lote urbano es operado por el mecanismo del mercado informal de suelo (Maldonado, 2005; Jaramillo, 2001).

La existencia del mercado informal de suelo es atribuida a varios factores, especialmente a una legislación urbanística modernista que dialoga con los estratos de renta elevada de las ciudades latinoamericanas. El modelo de ciudad formal modernista de las elites de la región, que impone un conjunto de requisitos normativos, produjo una verdadera barrera institucional a la provisión de vivienda para los sectores populares (por ejemplo, aquellos que están por debajo de tres salarios mínimos), e indujo a la acción irregular y/o clandestina de loteadores y a procesos de ocupación popular de parcelas urbanas y periurbanas (Rolnik, 1999; Maricato, 2001). Esa manifestación de movimientos de ocupación y/o de surgimiento de mercados informales de suelo urbano se repitió en prácticamente todos los países latinoamericanos. En este sentido, ese doble movimiento se constituye en una de las principales características de la formación socioespacial de las grandes ciudades de la región.

En el marco de esta característica estructural de la formación social y urbana latinoamericana, el retorno - o la reafirmación - del mercado de suelo se constituye en una fuerza que potencia la producción de una estructura socioespacial desigual. Pero este mercado reaparece con la asunción de dos formas institucionales diferentes: una formal, esto es, en el marco de un Estado de derecho; y una informal. En pocas palabras: el mercado informal popular de suelo urbano crece en prácticamente todos los países de América Latina y se transforma en un importante mecanismo de provisión de suelo y de vivienda para los sectores populares. La excepción de esta situación general es el caso de Chile, donde, en los últimos años, la política neoliberal de provisión habitacional ha reducido de forma sustantiva el déficit habitacional del país (Sabatini, 2003). Pero el relativo éxito del caso chileno se revela como paradójico. Su política habitacional fue elaborada con el objetivo de producir vivienda a través del mercado de viviendas populares, y así formalizar lo informal. Esta política se inició durante la dictadura de Augusto Pinochet, con el objetivo de acabar con los asentamientos informales denominados en el país como "campamentos", vistos, en ese entonces, como focos potenciales de resistencia a dicho régimen. Esta modalidad de intervención sobrevivió al régimen militar y fue incorporada como una de las principales políticas públicas de los gobiernos posdictadura. No obstante, en los últimos diez años, algunos indicadores referidos a las características de los conjuntos habitacionales de dicho país revelan dos fenómenos inesperados: un aumento importante de los precios de la tierra (urbana y periurbana) -y el consiguiente desplazamiento de los nuevos conjuntos hacia áreas mucho más distantes de los núcleos urbanos (Sabatini, 2005) - y, paralelamente, un rápido proceso de informalización de lo formal (Rodríguez y Sugranyes, 2005). El retorno de la informalidad en las áreas formales de los conjuntos habitacionales tiene dos dimensiones: la primera, de naturaleza urbanística; y la segunda, económica: el surgimiento de un mercado informal en esos conjuntos habitacionales. 
Así, la extensión del mercado informal de suelo es una realidad en las grandes ciudades latinoamericanas, y las expectativas de adopción de políticas neoliberales de titulación, fomentada por las agencias internacionales con el asesoramiento intelectual de Hernando de Soto, puede potenciar esta tendencia (Fernandes, 2003). En el próximo apartado se presentarán algunos elementos para una primera aproximación al funcionamiento del mercado informal de suelo y sus consecuencias, en términos de uso del suelo y de estructura urbana en las áreas informales urbanas.

\section{Hacia un encuadramiento del mercado informal de suelo: ¿qué es el mercado informal?, ¿̨realmente existe?}

La definición misma de "informalidad" (Azuela, 2001) es una cuestión delicada y objeto de muchas discusiones. Tal debate no será reproducido aquí. Más bien, se examinará la noción de informalidad urbana y uso del suelo que sirve de sustento a la exposición. La primera observación al respecto es que 'informalidad' no es un concepto, como explotación, marginalidad, expoliación u otros que sirven para una descripción de los fenómenos urbanos latinoamericanos. En la perspectiva aplicada en este trabajo, el término es tomado como descriptivo y, por lo tanto, preanalítico. La informalidad, en su sentido descriptivo y polisémico, sirve para definir fenómenos en varias disciplinas (economía, sociología, lingüística, antropología, derecho, etcétera) y situaciones concretas de la vida social. En este texto se restringe su uso a la dimensión urbana propiamente dicha, esto es, aquella que remite al uso del suelo urbano.

La primera aproximación al término 'informalidad' se hace a partir de la definición propuesta por Bagnasco (1999), que remite al campo disciplinar del derecho.

Llamamos economía formal al proceso de producción e intercambio de bienes y servicios regulados por el mercado y promovidos y realizados por empresas industriales y comerciales, con el objetivo del lucro y que actúan sometidas a las reglas del derecho comercial, fiscal, del trabajo, etc.; podemos llamar economía informal a todo el proceso de producción y de intercambio que no se somete a uno de estos aspectos. (p. 36)

Bagnasco concluye su definición con las siguientes recomendaciones:

El aspecto más complicado, y efectivamente el más interesante, de esa diferenciación está en el hecho de que los elementos formales e informales están imbricados en estructuras de acción social (...) la conclusión importante que podemos sugerir sería que la economía informal, en cuanto tal, no debería estar en el centro de la investigación [académica], sino, sobre todo, en el juego entre lo formal y lo informal en las estructuras reales de acción. (p. 37)

Aplicadas al mercado de suelo urbano, dos lecciones interesantes surgen del texto citado de Bagnasco. La primera tiene relación con una definición minimalista de economía informal urbana, donde esta sería un acto mercantil de comercialización 
y/o alquiler de suelo (edificado) que estaría fuera del marco institucional del derecho urbanístico, del derecho económico y comercial, del derecho de propiedad y de los otros derechos civiles que regulan el uso y la propiedad del suelo urbano. Es decir, el mercado informal comercializa un bien (material o inmaterial) al margen del marco regulador de la esfera jurídico-política del Estado de derecho moderno.

Siguiendo la aproximación de Bagnasco, la informalidad urbana sería un conjunto de irregularidades - o (a)regularidades - en materia de derechos: irregularidad urbanística, irregularidad constructiva e irregularidad en relación con el derecho de propiedad de la tierra (Alegría, 2005). En el caso del mercado informal de suelo, la informalidad de la economía del uso del mismo remite a esas tres irregularidades, pero también a otras, relativas a los contratos del mercado que norman las transacciones mercantiles. De esta manera, el mercado informal también sería (i)regular o (a)regular en relación con los derechos económicos, lo que lleva a que este particular mercado de uso del suelo sea la sumatoria de dos dimensiones de la informalidad: la urbana y la económica.

La mayor parte de los economistas diría que el mercado es regulado por instituciones fuertes que garantizan que su regularidad corresponda a los marcos de los derechos legales, esto es, aquellos derechos que estarían contemplados y garantizados por un sistema jurídico asociado al Estado. Para los economistas institucionalistas tradicionales (neo-institucionalistas), las instituciones informales en las relaciones de mercado - de existir- estarían subordinadas a las legales y servirían para aumentar su eficacia institucional, esto es, minimizar los costos de transacción (Williamson, 1985).

A partir de ese encuadramiento, se puede intentar superar la definición de informalidad de la economía institucionalista tradicional y acrecentar la posibilidad de existencia de un conjunto de instituciones y normas informales producidas históricamente en los asentamientos populares por la vía de las prácticas sociales, las cuales, de hecho, configuran un sistema de regulación informal de las transacciones mercantiles informales. Proponemos, entonces, una segunda calificación para la existencia de un mercado informal. El mercado informal del suelo debe estar fuera de los marcos de los derechos, pero debe tener una estructura institucional propia que garantice la reproducción temporal de las prácticas mercantiles informales de compra, venta y alquiler de suelo y/o inmuebles. En otras palabras, el mercado informal debe tener instituciones informales que permitan su funcionamiento y garanticen, en términos intertemporales e intergeneracionales, los contratos de naturaleza implícita establecidos en las transacciones informales de mercado.

En el caso del mercado informal de suelo, donde existen irregularidades (informalidades) respecto a la titulación y a las normas urbanísticas y constructivas, los contratos de compra, venta y alquiler no podrían ser considerados como tales, con el amparo de la ley, pues sus objetos serían irregulares en relación con los derechos regulatorios. Esto significa que dichas transacciones no serían objeto de la regulación y de las sanciones que sirven de garantía a los agentes envueltos en todas las relaciones contractuales de la economía formal, y que no cualquier conflicto puede ser resuelto por los instrumentos de mediación y ejecución legales. 
Cuando la ley no se constituye en el elemento de garantía de las relaciones contractuales del mercado, se deben desplegar otras formas de garantía para restablecer la confianza entre las partes involucradas en dichas relaciones. Cuando no existe confianza en que los contratos serán respetados, y no hay mecanismos coercitivos de cumplimento contractual entre las partes, ellos dejan de existir. Es decir, el mercado no se reproduce, o desaparece como mecanismo de coordinación de las acciones individuales (Bruni, 2006). En el caso del mercado informal y popular de suelo urbano, se deben construir socialmente otras formas de garantía para que las partes establezcan una relación de confianza en el respeto a los términos contractuales establecidos entre compradores y vendedores en el mercado de comercialización, o de locatarios y locadores en el mercado de alquiler. De lo contrario, en razón de la desconfianza mutua de un eventual rompimiento unilateral del contrato informal, la relación de intercambio mercantil no se realiza. En otras palabras, sin las instituciones formales, el mercado informal de suelo debe establecer sus propias instituciones reguladoras, incluyendo los mecanismos coercitivos en caso de rompimiento contractual de una de las partes (Abramo, 2012). Tales instituciones del mercado informal permiten que los contratos implícitos establecidos entre las partes sean respetados en términos intertemporales e intergeneracionales.

En el caso del mercado informal de suelo urbano, una base importante que garantiza su funcionamiento y su cadena contractual es la constituida por las relaciones de confianza y lealtad que las partes contratantes establecen entre sí. De esta manera, los compradores y los vendedores, así como los locadores y locatarios, depositan en el otro una relación de confianza que tiene como fundamento la expectativa de reciprocidad, a partir de una relación de lealtad. El cimiento de esta institución informal del mercado no es de carácter legal, sino que depende de la permanencia en el tiempo de una forma particular de interdicción social: la forma confianza-lealtad. Esta relación de reciprocidad interpersonal marca muchas relaciones sociales (Bruni, 2006); no obstante, en el caso de relaciones mercantiles fue excluida, por la característica del mercado de promover un encuentro contractual entre anónimos.

En el mercado informal y popular de suelo, donde la relación de reciprocidad confianza-lealtad es una de las instituciones fundadoras de la posibilidad de intercambio mercantil, surge la necesidad de una personalización de las relaciones contractuales. Esta personalización (alguien que vende o alquila y alguien que compró o alquiló) puede no ser totalmente transparente y asumir un carácter opaco, pero introduce la posibilidad de la relación de confianza-lealtad en la constitución de una relación contractual que, por definición, es implícita (informal); esto es, no está garantizada por los derechos que regulan los contratos económicos. Así, en el mercado informal de suelo, justamente, la eliminación de la im-personalización y la personalización de la relación contractual garantizan los mecanismo de confianza y lealtad que permiten un contrato de compra y venta o locación informal (Abramo, 2012). 
GRÁFICO 1 | Características informacionales del mercado informal de suelo en Brasil, 2006: fuente de la información sobre compras y alquileres

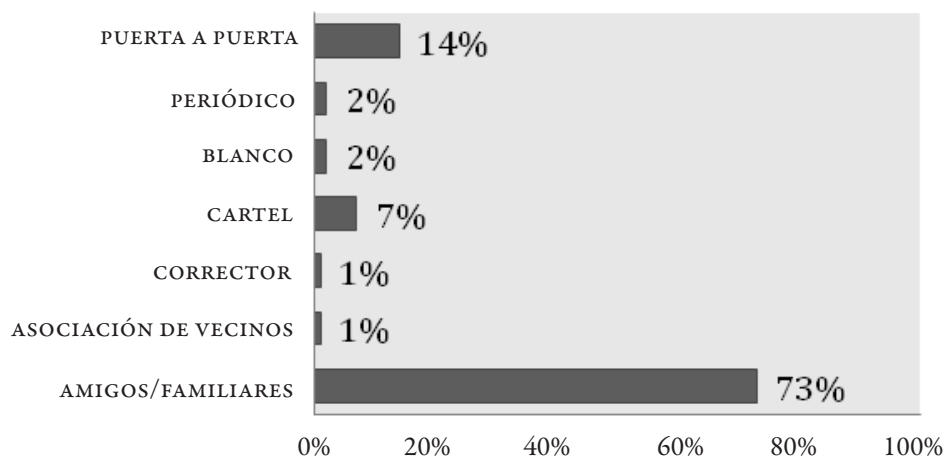

fUente Abramo (2006A).

El gráfico sobre las características informacionales del mercado informal en los asentamientos consolidados es muy significativo, puesto que revela que prácticamente todos los compradores y locadores tuvieron acceso a la información sobre los inmuebles o los lotes que compraron o alquilaron, a través de un pariente o amigo. Esta persona que sirvió de transmisor de la información del mercado es, a su vez, pariente o amigo de los vendedores y locadores, y actúa como una "argamasa interpersonal" en el establecimiento de la relación de confianza y lealtad entre las dos partes de la transacción del mercado informal de suelo. Así, los contratos mercantiles de este mercado informal están insertos en una trama de relaciones de amistad y/o parentesco que garantizan estabilidad temporal a las relaciones de confianza y lealtad entre los agentes que asumen una relación contractual (Abramo, 2012).

Pero el mundo del mercado informal de suelo no puede ser visto como un espacio donde no hay relaciones oportunistas y conflictivas entre las partes contratantes. Como dicen los poetas, el alma humana es un desconocido que se revela a partir de sueños, fantasmas, pasiones y odios. Así, los contratos mercantiles son una forma social de intermediación de relaciones personales que se establecen a partir de los cambios de posesión o de propiedad de bienes o servicios (tangibles o intangibles), que envuelven a hombres y mujeres con alma humana y, por lo tanto, susceptibles de cambiar de actitud o comportamiento en función de sus emociones, placeres, intereses y locuras. En este sentido, una trama de relaciones de amistad y/o parentesco, por más entrenada que sea, no garantiza la forma duradera y perfecta de las relaciones de confianza y lealtad en los contratos mercantiles del mercado informal de suelo. La posibilidad de una ruptura unilateral del contrato implícito y de la relación de confianza y lealtad sí existe, y será una amenaza para el funcionamiento del mercado informal. Aquí surge la necesidad de alguna mediación institucional que 
asuma la posición de un tercero, esto es, que esté por encima de las partes involucradas y cuya acción promueva el retorno a los términos del contrato informal inicial o, eventualmente, abra un espacio de negociación entre las partes, para redefinir los términos pactados anteriormente.

Esta figura de mediación contractual, que podemos llamar "autoridad", es determinante para el mantenimiento de los contratos informales y su permanencia en el tiempo, y garantiza la condición intertemporal e intergeneracional de los contratos del mercado informal de suelo. La hipótesis levantada a partir de investigaciones de campo sobre los mecanismos contractuales del mercado informal de suelo (Abramo, 2005b; y 2012, en prensa) es que en los asentamientos populares informales se constituye una "autoridad local" que sirve de figura mediadora de los conflictos en esa comunidad particular. Esas autoridades locales son el resultado de procesos históricos (de cada comunidad local) que atribuyen un lugar de autoridad a partir de una infinidad de sucesos sociales legitimadores. Esta legitimidad puede ser de naturaleza religiosa, étnica, cultural, política, o también puede darse a partir de la violencia y el control por la fuerza, según se constata en algunas investigaciones empíricas sobre el mercado informal en América Latina (Abramo, 2009). Como indican muchos estudios de la literatura de la antropología económica, los mecanismos de convivencia comunitaria que garantizan el orden social local exigen algún tipo de forma coercitiva para restringir y controlar los comportamientos conflictivos (o desviados). Estas formas pueden asumir la modalidad de una fuerza coercitiva colectiva pasiva, representativa y/o impositiva (Duty \& Weber, 2007).

En el caso del mercado informal de suelo, la autoridad local así definida sirve de institución mediadora de los conflictos contractuales, y permite que los contratos sean respetados y/o negociados entre las partes, garantizando, de esta forma, su mantenimiento intertemporal e intergeneracional. Muchos estudios antropológicos sobre la forma en que operan los mercados y las organizaciones formales describen las formas de coacción, que no se restringen a su dimensión legal (Duty \& Weber, 2007). De la misma manera, en el mercado informal de suelo es posible identificar formas y mecanismos coercitivos muy distintos, que sirven para garantizar lo que puede llamarse el "pacto contractual” de mercado.

La historia social y política de cada asentamiento ha construido y de-construido esos mecanismos coercitivos. Lo importante es que exista, efectivamente, una "autoridad local" que sirva de mediadora en los casos de ruptura y de conflictos en el cumplimiento de los contratos del mercado informal y, además, que disponga de mecanismos coercitivos (punición) en el caso de una mediación pacífica mal sucedida (Abramo, 2012). Estas dos características definen el núcleo básico de las instituciones informales del mercado informal de suelo.

Antes de intentar establecer una taxonomía de los submercados informales de suelo, es necesario devolverse a la segunda sugerencia de Bagnasco, que recuerda la importancia de no transformar la economía informal en un objeto, en sí mismo, de análisis. Este autor afirma que la mejor forma de entender la economía informal es a partir de su relación de interacción con la economía formal. En un trabajo anterior, 
subrayamos que las formas de interacción entre los mercados formales e informales de suelo pueden ser de naturaleza complementaria, de concurrencia o de efectos de borde, con mutua influencia en el comportamiento y estrategias de los agentes de los dos mercados (Abramo, 2006a). En el caso de este trabajo, se resaltará la interacción entre el mercado formal e informal de suelo a partir de sus resultantes agregadas, en términos de uso del suelo urbano; es decir, en la producción y reproducción de la forma urbana de las grandes ciudades latinoamericanas. Como se plantea en la introducción, el objetivo es demostrar que hay una similitud de resultados espaciales a partir del funcionamiento de los submercados formales e informales. Como se verá luego, el funcionamiento de estos dos submercados produce, simultáneamente, una estructura compacta y difusa del uso del suelo. Además, en los dos submercados se encuentran fuerzas de retroalimentación de la dinámica de producción de la estructura urbana com-fusa.

\section{Los dos submercados de suelo informal urbano}

El mercado de tierras informal puede ser clasificado en dos grandes submercados inmobiliarios. Tradicionalmente, la literatura de la economía del uso del suelo utiliza el criterio de "sustituibilidad" de los bienes raíces y/o inmobiliarios para definir dichos submercados. Con el conjunto de criterios que se presentan a continuación, se puede clasificar esquemáticamente el mercado popular informal de suelo urbano de la siguiente manera:

\section{Submercado de loteos $^{1}$ (urbanizaciones pirata)}

$$
\begin{cases}\bullet & \text { clandestinos } \\ \bullet & \text { irregulares }\end{cases}
$$

2. Submercado en los asentamientos populares informales (API) consolidados

$$
\left\{\begin{array}{l}
\text { residencial } \\
\text { comercial }
\end{array}\right.
$$$$
\begin{aligned}
& \left\{\begin{array}{l}
\text { comercialización } \\
\text { alquiler }
\end{array}\right. \\
& \left\{\begin{array}{l}
\text { comercialización } \\
\text { alquiler }
\end{array}\right.
\end{aligned}
$$

Incorporamos la definición de "insustituibilidad" como una de las variables clave para una construcción axiomática de los estudios sobre la estructura del mercado, y analizamos otros elementos considerados importantes para una primera aproximación al mercado informal. Así, definimos como elementos determinantes de la estructura del mercado los siguientes: características de la oferta y de la demanda de

1 Se utilizan indistintamente los términos loteamientos o loteos, ya que ambos se aplican en América Latina, dependiendo del país. 
suelo; poder del mercado de los agentes económicos (oferta y demanda); características informacionales del mercado (asimetrías y transparencias de información); características de los productos (homogéneos o heterogéneos); externalidades (exógenas y endógenas); racionalidades de los agentes (paramétrica, estratégica, etcétera); y ambiente de la toma de decisión (riesgo probabilístico o incertidumbre radical). La identificación de estas variables aproxima conceptualmente este abordaje del mercado informal al tratamiento moderno de la teoría económica del mercado, permitiendo, por lo tanto, acotar conceptualmente las particularidades del mercado informal de suelo y sus semejanzas con los otros mercados formales de la economía. A partir de estos puntos, se intenta determinar diferencias sustantivas en los mercados de tierra informal, a fin de establecer una primera aproximación a la definición de submercados informales. El resultado de este ejercicio puede ser visto en el Cuadro 1, sobre las características estructurales del mercado informal, y permite distinguir dos grandes submercados de suelo informal: submercado de loteos y submercado de áreas consolidadas (Abramo, 2009; 2006a; 2003b).

CUADRO 1 | Marco comparativo de las características del mercado informal de loteos y el mercado informal en asentamientos populares consolidados

\begin{tabular}{|c|c|c|}
\hline & LOTEOS & ASENTAMIENTOS CONSOLIDADOS \\
\hline ESTRUCTURA DE MERCADO & Oligopólica & Concurrencia con mercado "racionado" \\
\hline $\begin{array}{l}\text { AGENTE DOMINANTE } \\
\text { Y DETERMINACIÓN DE } \\
\text { PRECIOS }\end{array}$ & $\begin{array}{l}\text { Fraccionador con capacidad de } \\
\text { realizar mark up urbano }\end{array}$ & $\begin{array}{l}\text { Comprador ("entrante") y vendedor } \\
\text { ("saliente"); tensión entre oferta y } \\
\text { demanda }\end{array}$ \\
\hline $\begin{array}{l}\text { ASIMETRÍA DEL PODER } \\
\text { DE MERCADO }\end{array}$ & Fuerte & Variable \\
\hline $\begin{array}{l}\text { CARACTERÍSTICA DEL } \\
\text { PRODUCTO }\end{array}$ & $\begin{array}{l}\text { Homogeneidad relativa (lote), con } \\
\text { variaciones de la ubicación y metraje }\end{array}$ & Heterogeneidad \\
\hline EXTERNALIDADES & $\begin{array}{l}\text { Exógenas (jerarquía de accesibilidad } \\
+ \text { características físicas y } \\
\text { topográficas) }\end{array}$ & Endógenas + exógenas \\
\hline $\begin{array}{l}\text { RACIONALIDAD Y } \\
\text { ANTICIPACIÓN }\end{array}$ & $\begin{array}{l}\text { Estratégica, con información } \\
\text { incompleta (juego de la anticipación } \\
\text { de infraestructura) }\end{array}$ & $\begin{array}{l}\text { Pluralidad de racionalidades y objetivos } \\
\text { de anticipación }\end{array}$ \\
\hline INFORMACIÓN & Incompleta e imperfecta (riesgo) & $\begin{array}{l}\text { Asimetría informacional e } \\
\text { imprevisibilidad (incertidumbre radical) }\end{array}$ \\
\hline
\end{tabular}

FUENTE ELABORACIÓN PROPIA. 
El primero de esos submercados (loteos) es, en gran medida, definido por una estructura oligopólica de mercado. En cuanto al segundo (áreas consolidadas), presenta una estructura competitiva, pero con una oferta racionada; es decir, la oferta en el submercado de áreas populares informales (API) consolidadas es estática en relación con su aumento. Como se verá más adelante en la descripción del circuito perverso de retroalimentación de los submercados, esa característica de estatismo tendrá un papel importante en el aumento de los precios informales en áreas consolidadas, induciendo a que algunas familias se trasladen a la periferia por la puerta de acceso del mercado informal de loteos. En otras palabras, la oferta racionada en el submercado en áreas consolidadas generará una demanda potencial para el submercado de loteos informales.

Los dos submercados de suelo informal pueden ser identificados en la estructura urbana de la ciudad, en áreas precisas y con distintas funcionalidades en el proceso de vertebración urbana. En el primer submercado opera el fraccionamiento de predios en la periferia de las ciudades, que constituye el principal vector de expansión de la malla urbana y de la dinámica de periferización precaria, cuya característica principal, en las grandes ciudades latinoamericanas, es la inexistencia (o precariedad) de infraestructuras, servicios y accesibilidad. La lógica de funcionamiento de ese mercado de lotes es oligopólica en la formación de sus precios, pero las prácticas de definición de los productos y de su financiamiento remiten a las tradiciones mercantiles premodernas, donde la "personificación opaca" adquiere un papel importante de ajuste de la oferta de las preferencias y la capacidad de gasto de la demanda.

La estructura oligopólica en la formación de los precios es uno de los factores de la alta rentabilidad mercantil de esa actividad, pero la flexibilidad en el ajuste de los productos y en la adecuación familiar de las formas de financiamientos informal es un factor de atracción para los sectores populares. Estas dos características articulan el aspecto de modernidad oligopólica y de flexibilidad posmoderna en relación a la oferta de lotes informales, con una dimensión tradicional de personalización de la relación mercantil. Se define así un nexo moderno-tradicional de naturaleza nueva en el mercado informal, que asegura su atracción tanto para los "urbanizadores piratas" como para la demanda popular. Los productos de este submercado de lotes son relativamente homogéneos y sus principales factores de diferenciación remiten a dimensiones físicas, topográficas y a las externalidades exógenas relativas a la posición del loteo en la jerarquía de accesibilidades y de infraestructuras urbanas. En este sentido, la producción informal de lotes puede adquirir una cierta economía de escala, aunque la temporalidad de su venta es muy inestable y depende de factores externos a las variables del propio mercado informal.

La lógica de formación de los precios en el submercado de loteos informales obedece a una composición de factores que, sumados, definen el precio final de los lotes informales. Grosso modo, es posible listar los siguientes factores determinantes de los precios en el submercado informal de lotes: 
a) Factor ricardiano clásico, vinculado a los factores de los costos de fraccionamiento del predio. Así, las características topológicas y topográficas determinan costos de fraccionamiento diferenciados que serán incorporados al precio final del lote informal.

b) Factor thuneniano de localización. La ubicación del loteo en relación con su accesibilidad y la centralidad ponderada por los medios de transporte disponibles es un componente que también está incorporado en el precio final del lote.

c) Factor de anticipación de infraestructura y de servicios futuros. El loteador, al buscar lotes sin infraestructura urbana y al no proveerla para sus eventuales compradores, anticipa que el poder público asumirá estas atribuciones en el futuro. Así, los loteadores anticipan el valor de un área provista de infraestructura por el poder público y cobran, hoy, lo que será ofertado en el futuro. Esta ganancia anticipada varía en función de los cálculos del tiempo medio que le tomará al poder público proveer la infraestructura y los servicios urbanos básicos. Como se verá más adelante, el factor de anticipación será uno de los componentes más importantes de la ganancia de fraccionamiento del predio, y conduce a los loteadores a buscar parcelas baratas y con poca accesibilidad e infraestructura, pues este hecho permite un mayor margen de ganancia de anticipación por el agente que fracciona el predio. En términos espaciales, esto significa una búsqueda continua de nuevas áreas periféricas y, por lo tanto, un desplazamiento constante de la frontera urbana ocupada a partir del uso urbano (o periurbano) informal.

d) Factor de ajuste de mercado. Es un multiplicador o reductor de los precios en función de la concurrencia oligopolista entre los loteadores y/u otros submercados informales y formales. La relativa opacidad o transparencia del mercado de lotes informales puede servir de ponderador de los reductores y multiplicadores, pues cuanto más opaco es el mercado, en términos informacionales, menor es el peso de este factor en la determinación del precio final.

e) Factor de facilidad y flexibilidad en los términos de contratación de créditos informales. La mayor facilidad y flexibilidad en el acceso a un lote a partir de contratos informales de endeudamiento familiar (crédito) genera un interés (o beneficio financiero) de naturaleza informal. Este no está vinculado a las tasas básicas de crédito de la economía formal (tasa de interés fijada por el Banco Central y practicada por los agentes financieros formales), sino que será incorporado al precio final del lote.

Podríamos agregar los factores de naturaleza macro- o mesoeconómica, como el volumen de empleo, distribución de la renta, etcétera. Pero estos factores, en general, apenas desplazan hacia arriba o hacia abajo el gradiente de los precios relativos del suelo (Abramo, 2010a). En la perspectiva de relacionar el funcionamiento del mercado de suelo (formal e informal) con la producción de la forma urbana, lo 
importante es la variación de un precio en una localización-espacialidad particular en relación con los otros precios-localización; esto es, los precios relativos. En este contexto, la estrategia de los loteadores informales siempre será buscar parcelas con el fin de fraccionarlas, minimizando los costos de esta operación y maximizando los factores que les permiten apropiarse de las riquezas producidas por la variación de los precios relativos del suelo urbano. Dadas estas condiciones, la mejor estrategia, desde el punto de vista espacial, es la búsqueda de terrenos baratos y sin infraestructura en la franja de la ocupación urbana de suelo. El resultado, en términos de la forma de ocupación del suelo de la ciudad, es una tendencia a la extensión continua, que a su vez produce una estructura difusa de territorialidad de la informalidad urbana. En pocas palabras, el funcionamiento del submercado de loteos informales promueve la extensión del uso del suelo y su resultante es la producción de una forma difusa de territorio informal. En la cartografía de la informalidad de la ciudad de Río de Janeiro (Mapa 1) se puede ver claramente al submercado de loteos promoviendo un vector de extensión urbana.

\section{MAPA 1 | Localización de los loteos informales en Río de Janeiro}

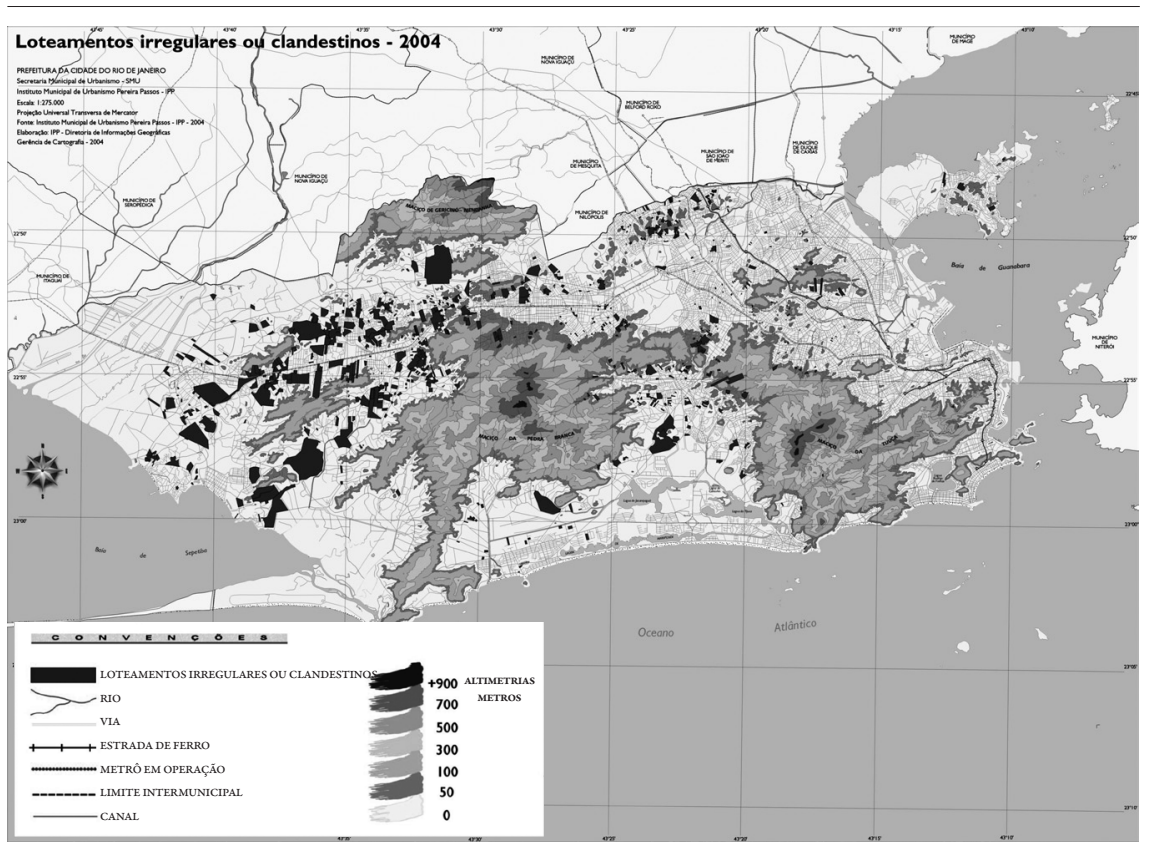

fuente Alcaldía de la ciudad de Río de Janeiro (2005).

El submercado de las áreas populares informales consolidadas presenta características distintas a las del submercado de loteos. Se expusieron algunas de ellas en el Cuadro 1, que establecía la distinción entre los dos submercados informales, y no 
se desarrollarán esas diferencias en este trabajo (Abramo, 2006a). ${ }^{2}$ El punto que se quiere resaltar es que las externalidades endógenas positivas en los asentamientos populares informales consolidados son muy importantes en la formación de los precios. En esta línea existen dos externalidades endógenas muy valoradas en el mercado informal de esos asentamientos. Una es la que denominamos "externalidad de libertad urbanística y constructiva”, que permite al comprador de un inmueble informal ejercer un derecho de uso del suelo (fraccionamiento y/o suelo creado) que no está regulado por los derechos urbanísticos y de propiedad de la legalidad vigente del sistema jurídico-político del Estado. La posibilidad de hacer un uso del suelo más intensivo, sin la mediación del Estado, puede ser vista como una libertad para aquel que tiene la posesión o propiedad informal, ya sea de un lote o de una edificación. Esta externalidad (libertad urbanística) será incorporada en los precios finales del mercado informal en áreas consolidadas, y también será un atractivo para la demanda de ese mercado (Abramo, 2006a y 2009). Utilizando la terminología tradicional, puede decirse que la libertad urbanística y constructiva es una ventaja comparativa importante en relación con el mercado formal de suelo, y al ser ejercida promueve un proceso de compactación en los asentamientos populares informales.

Una segunda externalidad endógena positiva en los asentamientos populares informales consolidados es lo que denominamos "externalidad comunitaria". Esta es el resultado de una economía de reciprocidades, donde las familias tienen acceso a los bienes y servicios a partir de relaciones de "Don" y "contra-Don" (Caillé, 2000), donde no se desembolsan valores monetarios para acceder a ciertos bienes y servicios. La externalidad comunitaria es sustentada por redes sociales y manifiesta dinámicas de proximidad organizada (Rallet \& Torre, 2007), las cuales permiten interacciones interfamiliares que se reproducen temporalmente en los mencionados lazos de "Don" y "contra-Don" y establecen mecanismos de intercambio basados en relaciones de confianza y lealtad (Pelligra, 2007).

La condición para entrar en esta economía de reciprocidades (que, según se indicó, garantiza el acceso a bienes y servicios sin comprometer una parte de los recursos monetarios familiares) es habitar en un asentamiento popular informal y tener relaciones de reciprocidad en ese barrio. Así, esa externalidad comunitaria tiende a ser capitalizada en los precios del suelo y es capturada por los vendedores del submercado en API consolidados (Abramo, 2009). Para la discusión sobre la forma de la territorialidad informal, el factor proximidad es un elemento valorado por el mercado informal de suelo. La demanda en ese mercado busca las externalidades de libertad urbanística y constructiva, junto a la externalidad comunitaria. Los resultados concretos de la práctica (usufructo) de esta externalidad consisten en la compactación del territorio informal de los asentamientos populares con el fraccionamiento de los lotes, el aumento de la densificación predial y familiar, y la tendencia a la verticalización informal. De esta misma manera, la existencia y el mantenimiento de las

Véase Abramo (2009 y 2012), para una discusión detallada y de naturaleza conceptual sobre las formas de funcionamiento del mercado informal, y sus similitudes y diferencias en relación con el funcionamiento del mercado formal. 
externalidades comunitarias dependen de la dinámica de aglomeración territorial y de los lazos sociales (redes) que se formen a partir de esta aglomeración. Así, las dos externalidades positivas más importantes del submercado informal de suelo en áreas consolidadas promueven y se nutren de la compactación espacial.

CUADRO 2 | Estrategias de los agentes de los submercados informales de suelo urbano

Estrategias de los agentes de los submercados informales de suelo urbano

\begin{tabular}{c}
$\begin{array}{c}\text { Submercado de asentamientos consolidados } \\
\text { Economía de la proximidad }\end{array}$ \\
\hline ESTRUCTURA COMPACTA \\
Submercados de loteos \\
Economía de reducción de costes \\
ESTRUCTURA DIFUSA
\end{tabular}

FUENTE ELABORACIÓN PROPIA.

Por lo tanto, puede levantarse la hipótesis de que el funcionamiento del submercado informal en los API consolidados está estimulado por una búsqueda de efectos de aglomeración de compactación, cuyo resultado en términos de uso del suelo es una intensificación del mismo y, por lo tanto, una compactación del territorio informal consolidado.

Un tercer factor que incide en el proceso de compactación de las áreas consolidadas informales es el aumento, en las dos últimas décadas, de los costos de transporte, que se refleja en un mayor peso de este rubro en el presupuesto familiar de los sectores populares. El fenómeno de las "súper-periferias" revela su aspecto perverso y de inequidad social, por ejemplo, en el creciente gasto familiar en relación con los costos de traslado. Una respuesta de estos grupos sociales puede ser la decisión de cambiar su domicilio hacia áreas con mayor accesibilidad. Los datos censales en muchos países revelan lo que podría llamarse el "retorno" de los pobres al centro; en la mayoría de los casos, la forma de regresar es por la vía del mercado informal en las áreas consolidadas.

Como ya se dijo, el submercado informal en las áreas consolidadas se divide en dos: el submercado de comercialización (compra y venta de lotes, casas y departamentos) y el submercado de alquiler. Ante la imposibilidad de ocupar el suelo en las áreas centrales y el impedimento para tener acceso al suelo formal, el mecanismo social de retorno de los pobres a la centralidad será el mercado informal de comercialización y de alquiler. Resultados de investigaciones recientes sobre los mercados 
informales revelan la importancia del submercado de alquiler informal como vía de provisión habitacional para los sectores populares (Abramo, 2010b). El Cuadro 3 muestra que en muchas ciudades latinoamericanas el submercado dominante en las áreas populares informales es el de alquiler.

CUADRo 3 | Tipo de submercado residencial predominante en los API, año 2006

\begin{tabular}{l|l}
\hline CIUDAD/PAís & SUBMERCADo \\
\hline Buenos Aires (Argentina) & Alquiler \\
Bogotá (Colombia) & Alquiler \\
Ciudad de México (México) & Comercialización \\
Lima (Perú) & Alquiler/ Comercialización \\
Caracas (Venezuela) & Alquiler \\
Río de Janeiro (Brasil) & Comercialización \\
\hline
\end{tabular}

FUENTE Abramo (2006B).

Se observa que en Bogotá, Caracas y en algunas metrópolis brasileñas el mercado de locación es dominante y desempeña un papel importante en el acceso de los pobres al suelo urbano. No cabe la menor duda de que el crecimiento del mercado informal de alquiler es un fenómeno reciente y la oferta de ese mercado es el resultado de un uso más intensivo del suelo en los asentamientos consolidados. La oferta de alquiler informal, en general, resulta de fraccionamientos y/o la extensión de la unidad residencial o la subdivisión del lote original con edificación. En los dos casos, el resultado es un uso más intensivo del suelo o, por lo tanto, una compactación de los asentamientos informales.

El caso de Río de Janeiro es bastante representativo de ese crecimiento. En la investigación realizada en el año 2002 (Abramo, 2003b), se verificó que la participación del mercado de alquiler informal representaba $15 \%$ del mercado de suelo en los asentamientos populares informales consolidados. En apenas cuatro años, para 2006, esa participación pasó a ser de 29\%, y la locación informal creció en prácticamente todos los asentamientos (favelas) estudiados (Abramo, 2010b). Al examinar la distribución del tipo de producto dominante en el mercado de locación, se constata que los inmuebles más demandados son aquellos que tienen apenas un cuarto. El predominio de pequeñas unidades habitacionales en el mercado informal de locación alimenta la tendencia a la compactación informal. Así, dos movimientos fomentan el proceso de compactación a través del mercado de alquiler informal: el primero consiste en la transformación de algunos moradores de los asentamientos en arrendadores informales, al fraccionar sus viviendas y/o lotes para atender la creciente demanda de locatarios en áreas informales consolidadas. El segundo movimiento se centra en la preferencia de los locatarios informales por pequeñas 
unidades, en función de su reducida capacidad adquisitiva. En general, estos inmuebles de locación informal presentan una fuerte densidad habitacional, lo que da origen a una precarización de lo que ya era precario (Abramo, 2010b). Tanto el movimiento de la oferta de alquiler informal como el de la demanda potencian la tendencia hacia la compactación de las áreas informales consolidadas.

CUADRo 4 | Producto dominante del mercado de alquiler por país, año 2006

\begin{tabular}{l|l}
\hline CIUDAD/PAís & PRODUCTO DOMINANTE \\
\hline Buenos Aires (Argentina) & 1 cuarto $(89,8 \%)$ \\
Río de Janeiro (Brasil) & 1 cuarto $(79,4 \%)$ \\
Bogotá (Colombia) & 2 cuartos $(42,7 \%)$ \\
Ciudad de México (México) & 2 cuartos $(42,2 \%)$ \\
Lima (Perú) & 1 cuarto $(56,2 \%)$ \\
Caracas (Venezuela) & 1 cuarto $(40,3 \%) / 2$ cuartos $(38,4 \%)$ \\
\hline
\end{tabular}

FUente Abramo (2006B).

La explicación del crecimiento del mercado de alquiler informal lo asocia a la precarización del mercado de trabajo, pero también a una dinámica intergeneracional, donde la capacidad de ahorro familiar es prácticamente inexistente y el capital inicial necesario para adquirir un lote o una casa precaria simplemente no existe. El relato de una jefa de familia en Florianópolis retrata de forma ejemplar esta situación (Sugai, 2007): "Yo pago alquiler, pago más de la mitad de mi salario y la gente aquí dice que con ese dinero podía dejar el alquiler y pagar un lote más lejos, pero yo pago el lote, ¿y dónde voy a vivir? Yo no tengo dinero para colocar una casa en pie. Así, tengo que quedar en el alquiler... aun siendo tan caro".

El relato nos revela la incapacidad de ahorro familiar para comprar un lote e iniciar un proceso de edificación progresiva, clásico en los loteos informales populares; y también deja claro que una de las razones para esta incapacidad de ahorro familiar está vinculada a los altos precios de los alquileres en relación con sus rendimientos. En otras palabras, el mercado informal de locación presenta una paradoja: al mantener precios relativos altos garantiza su demanda, cuando esta no es capaz de saltar hacia otro submercado informal de suelo, el mercado de loteo.

Otro factor que alimenta la oferta de alquiler informal es el estímulo a que las familias pobres complementen su inversión familiar fraccionando su unidad habitacional para fines de locación. En el mercado formal, el valor de alquiler de un inmueble tiende a ser inferior al $1 \%$ del valor de comercialización del mismo. En el Cuadro 6 se observa que las tasas de rentabilidad de locación informal en América Latina son superiores al valor de referencia de los barrios formales. 
CUADRo 5 | Precios medios de los alquileres en salarios mínimos por país, año 2006

\begin{tabular}{l|c}
\hline CIUDAD/PAís & ALQUILER \\
\hline Río de Janeiro (Brasil) & 0,75 \\
Buenos Aires (Argentina) & 0,24 \\
Ciudad de México (México) & 0,55 \\
Caracas (Venezuela) & 0,45 \\
Bogotá (Colombia) & 0,68 \\
Lima (Perú) & 0,08 \\
\hline
\end{tabular}

fuente Abramo (2006B).

CUADRO 6 | Rentabilidad del mercado de alquiler informal: relación entre precios medios de locación sobre precios medios de compra, por país, año 2006 (porcentajes)

\begin{tabular}{l|c}
\hline CIUDAD/PAís & ALQUILER/COMPRA \\
\hline Río de Janeiro (Brasil) & 2,37 \\
Buenos Aires (Argentina) & 2,28 \\
Ciudad de México (México) & 1,09 \\
Caracas (Venezuela) & 0,70 \\
Bogotá (Colombia) & 2,10 \\
Lima (Perú) & 1,51 \\
\hline
\end{tabular}

fuente Abramo (2006B).

En este sentido, puede afirmarse que hay un estímulo del mercado para la conversión de los espacios familiares en oferta en el mercado de locaciones informales. Esta incitación perversa puede reducir el indicador de habitabilidad en las áreas informales y representa, además, un estímulo a la compactación en los asentamientos consolidados informales. En otras palabras, desde el punto de vista de la forma de uso del suelo, el crecimiento del mercado de locación en las áreas populares informales potencia la tendencia del mercado informal a producir una compactación de esas áreas.

En los mapas siguientes se observa la cartografía de los dos grandes submercados informales de suelo en la ciudad de Río de Janeiro. En ellos es patente una clara distinción espacial entre el submercado de loteo y el submercado secundario de suelo en las áreas consolidadas. El primero se localiza en la periferia urbana, mientras el segundo lo hace en las áreas más centrales de la ciudad. Pero el elemento importante es el que señala que el funcionamiento del submercado en los asentamientos consolidados produce una estructura compacta, mientras el funcionamiento del submercado de loteos promueve una estructura difusa. 
MAPAS 2 y 3 | Cartografía de los submercados informales de suelo en la ciudad de Río de Janeiro
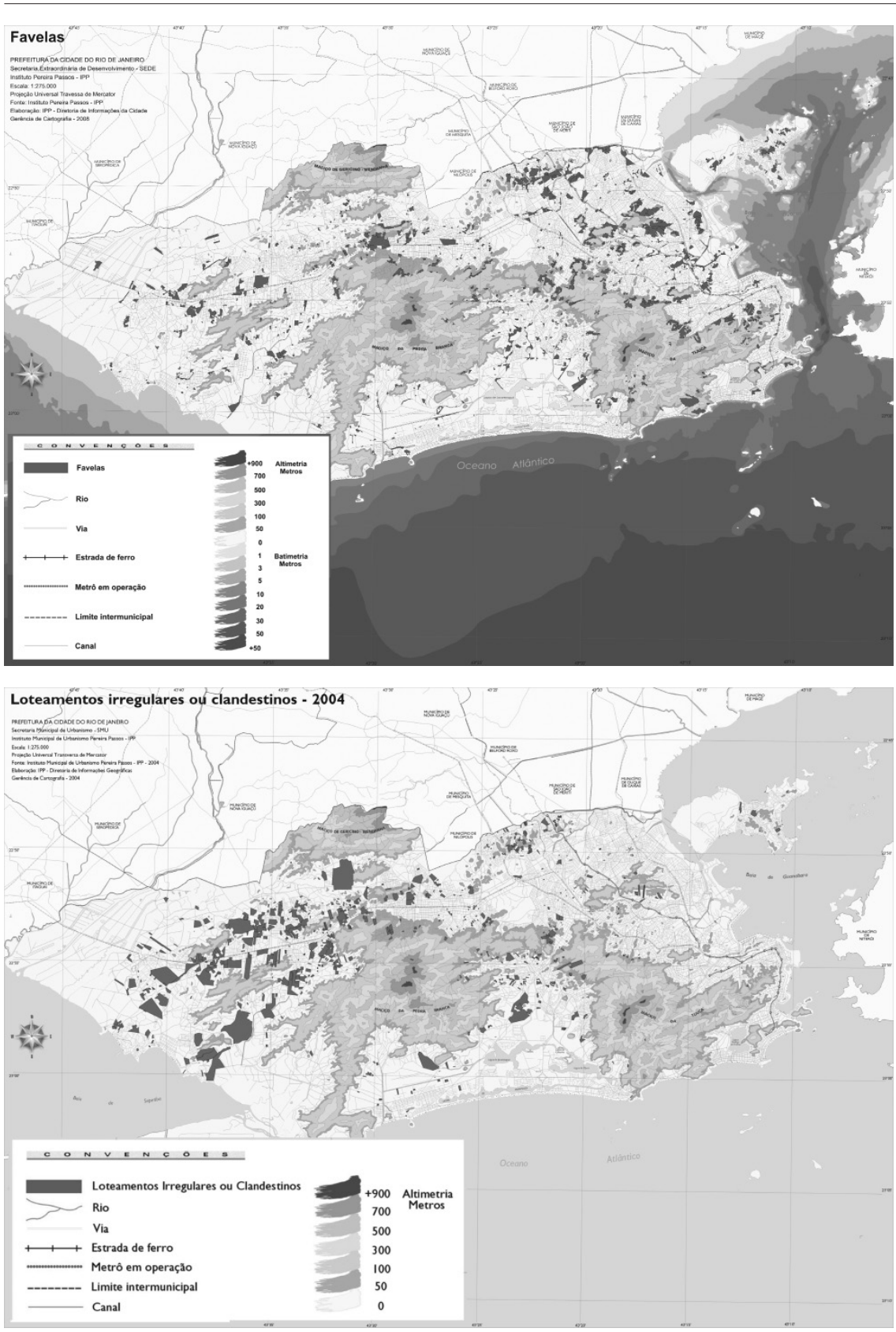

fuente Alcaldía de Río de Janeiro (2005). 
Lo que se puede verificar en términos de producción de la territorialidad informal en cuanto a las formas de funcionamiento del mercado informal de suelo es evidente: el submercado en API consolidados promueve una "ciudad informal" compacta $_{2}$ mientras el submercado de loteo produce una "ciudad informal" difusa. Es decir, el funcionamiento del mercado informal de suelo para los sectores populares produce una estructura urbana com-fusa (compacta y difusa a la vez).

\section{El círculo perverso de la retroalimentación de los dos submercados informales de suelo}

El hecho de que los dos submercados informales produzcan una estructura com-fusa del uso del suelo urbano informal es grave, pues promueve una doble precarización: del hábitat y de la reproducción de la vida popular. El mercado informal, al promover un territorio cada vez más difuso, impone costos de transporte crecientes a los trabajadores que viven en esos loteos; además, cuando el mismo mercado produce una compactación en los asentamientos consolidados, se promueve una precarización del hábitat popular, por el aumento de densidad (predial y habitacional) y verticalización, con todas las implicaciones que ello tiene en los indicadores de habitabilidad (escasez de aire, sol, etcétera) que esa compactación promueve. En términos macrosociales, la existencia y la continuidad del mercado informal de suelo están vinculadas a la desigualdad en la distribución de la renta y la incapacidad del poder público de promover una oferta masiva y regular de viviendas. Por eso, deseamos subrayar otro elemento que no está necesariamente relacionado con el aumento de la precariedad laboral o la incapacidad de acción pública, pero que sirve de motor y alimenta el funcionamiento de los dos submercados informales de suelo. Nos referimos a su atractividad para los sectores populares (externalidades positivas de constructibilidad y externalidad comunitaria), además de la alta rentabilidad mercantil en las transacciones de compraventa de los mercados informales de suelo.

Al caracterizar el funcionamiento de ambos submercados, se advierte la existencia de una tendencia de retroalimentación entre ellos, donde el submercado de loteos genera una demanda para el submercado en las áreas consolidadas, y viceversa. Se da, así, una forma de funcionamiento de los submercados informales de suelo donde uno promueve la demanda del otro, de forma continua y circular. Esta dinámica de demanda de suelo informal que se autogenera crea un sistema cerrado, que al provocar efectos de retroalimentación reproduce, en escala creciente, la estructura com-fusa de la territorialidad popular informal.

En el Diagrama 1 se esquematiza el circuito perverso de retroalimentación de los dos submercados informales de suelo. Se observa que el funcionamiento del submercado de loteos informales, al promover una ciudad cada vez más difusa, impone un costo de transporte creciente a la población que decide habitar en una periferia que es cada vez más distante del centro. De la misma forma, la precarización del mercado de trabajo y el crecimiento de la participación de trabajos eventuales exige la presencia física de ese trabajador en alguna centralidad, imponiendo un costo de 
traslado que no necesariamente será compensado con el rendimiento diario. Una salida para estas familias es retornar a la centralidad. Pero para realizar tal cosa, deben regresar por la puerta del mercado informal en áreas consolidadas, ya sea por la "mano" del mercado de comercialización, o por la "mano" del mercado de locación. Así, el funcionamiento del submercado de lotes produce una demanda para el submercado en las áreas consolidadas. No obstante, el crecimiento de la demanda en el submercado en áreas consolidadas no puede ser respondido con una mayor oferta, en razón de su relativa rigidez.

DIAGRAMA 1 | Círculo perverso de retroalimentación de los dos submercados informales de suelo

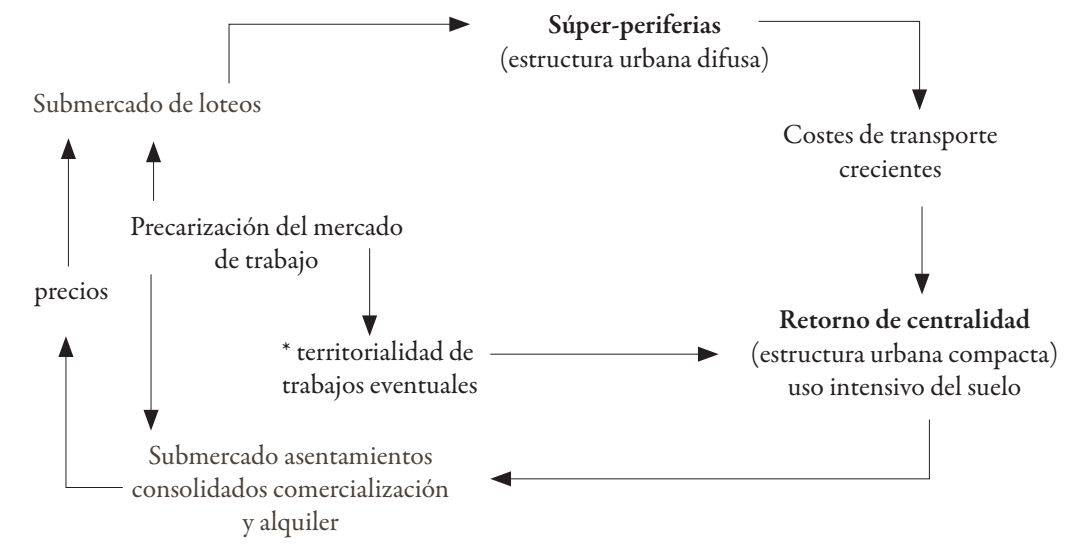

FUENTE ELABORACIÓN PROPIA.

Así, la reacción del mercado ocurre a través de los precios, pues estos tienden a elevarse. Se da, entonces, un aumento de la intención de las familias que ofrecerán sus inmuebles o lotes en las áreas consolidadas y se capitalizarán (o descapitalizarán) para comprar un lote en la periferia y construir viviendas con mejores (o peores) condiciones de habitabilidad. Otra vez, el funcionamiento de un submercado informal alimenta la demanda de otro; en este caso, el submercado en las áreas consolidadas generó una demanda para el submercado en la periferia. Este efecto de retroalimentación, como se dijo, es perverso, pues produce una estructura urbana informal más compacta en las áreas consolidadas y más difusa en las franjas urbanas; la "ciudad informal" com-fusa es portadora de una precarización del hábitat popular, así como de una pérdida de eficiencia en el uso del suelo urbano. También se puede afirmar que el circuito perverso de retroalimentación promueve un aumento de los precios del mercado informal de suelo, incrementando las distribuciones regresivas de la riqueza capturada en la forma de valorización del suelo. 


\section{La ciudad caleidoscópica: el territorio com-fuso formal ${ }^{3}$}

El mercado es el principal vector de estructuración del uso residencial del suelo formal de las grandes ciudades latinoamericanas. Al contrario del mercado informal, las instituciones reguladoras de este mercado están inscritas en el ordenamiento del sistema jurídico-político del Estado. Por eso, este mercado tiene una serie de peculiaridades que lo tornan particular en relación con otros de la economía capitalista. Sus tres principales características distintivas son: i) la inmovilidad territorial del bien inmobiliario; ii) su alto valor individual; y iii) su largo periodo de depreciación. Cada una de estas características implica un problema para la reproducción del capital inmobiliario. La inmovilidad impide que ese bien, producido sobre un soporte locacional específico, sea eventualmente trasladado a otro mercado-localización (barrio, ciudad, país). El alto valor individual del bien inmueble impone que la demanda asuma un compromiso de sus rendimientos familiares futuros, pues la adquisición del bien inmueble, en general, involucra una decisión de endeudamiento familiar. Y el largo periodo de depreciación, setenta años en promedio, es un factor que condiciona, en el corto y el mediano plazo, el retorno de la demanda atendida en el mercado, lo que condiciona, por lo tanto, la demanda habitacional a fenómenos de tipo demográfico (ciclo familiar, migraciones, etcétera).

Además de estas características, el mercado formal en las grandes ciudades latinoamericanas está altamente segmentado en términos de capacidad de compra de la demanda. Esta segmentación de la capacidad adquisitiva y solvente de la demanda es la expresión de desigualdad en la distribución de la riqueza en el mercado inmobiliario. La forma en que los capitales inmobiliarios se liberaron de esas restricciones estructurales del mercado en América Latina fue mediante la creación de un mercado inmobiliario altamente segmentado. Esta disociación responde a dos órdenes de motivos diferentes: desde el punto de vista de la oferta — es decir, de los capitales inmobiliarios-, la segmentación de la demanda permite una reducción de los riesgos y de las incertidumbres de los emprendimientos inmobiliarios; y desde el punto de vista de la demanda (unidades familiares), la segmentación del mercado garantiza una relativa homogeneidad socioespacial de su entorno residencial.

En otras palabras, una estructura de oferta residencial segmentada en términos socioeconómicos promueve una estructura espacial fraccionada en términos socioespaciales. Este tipo de estructura residencial ("segregada”, según algunos autores) se manifiesta como un mecanismo de "distinción espacial jerarquizada", que reitera espacialmente las divisiones de clase y la estratificación socioeconómica (Bourdieu, 1994). Así, la segmentación de la oferta, promovida por los capitales, y la búsqueda de fragmentación (distinción espacial) de la demanda se articulan funcionalmente y definen una forma de actuación de los capitales inmobiliarios en las grandes metrópolis latinoamericanas. Esta dinámica de valorización de los capitales inmobiliarios produce lo que denominamos una "ciudad caleidoscópica” (Abramo, 2011).

En este ítem, retomamos los argumentos desarrollados en Abramo (2011). 
En trabajos anteriores (Abramo, 2010a) discutimos de forma conceptual y empírica las motivaciones de la demanda residencial en el mercado formal y concluimos que el factor determinante de las elecciones residenciales es una búsqueda de distinción socioespacial, pues las familias desean estar próximas a sus semejantes. El deseo de cercanía de los semejantes se concretiza en una externalidad de vecindad que preferimos llamar "convención urbana" (Abramo, 2011). En una sociedad estratificada, el patrón de comportamiento de desear estar junto a los semejantes produce una cascada de movimientos de rechazo a los no-semejantes, desde lo alto de la pirámide social hacia abajo. Así, las convenciones urbanas son jerarquizadas y sirven de mecanismo cognitivo, un mecanismo que garantiza la estructura segmentada y jerarquizada de las externalidades de vecindad y, por lo tanto, de la estructura socioespacial urbana segmentada (segregada) y desigual.

DIAGRAMA 2 | La búsqueda de distinción socioespacial: la externalidad de vecindad

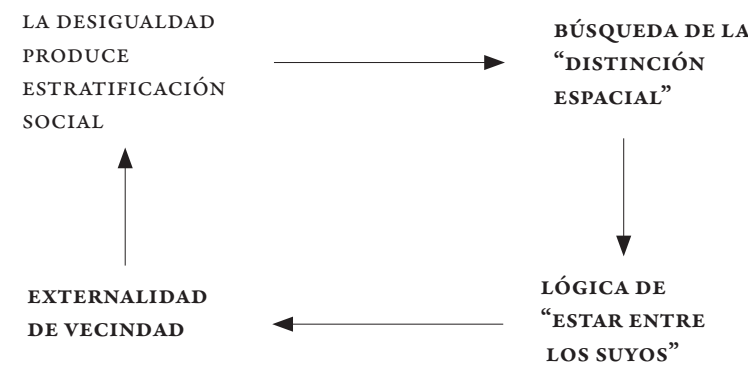

FUENTE ELABORACIÓN PROPIA.

La convención urbana es una externalidad de vecindad que no necesariamente está inserta en una territorialidad específica; esta no está definida por factores naturales, pero sí por el carácter de interacción socioespacial de sectores del mismo estrato social (o cultural, étnico, etcétera). Esta característica de la externalidad de vecindad como un proceso de emergencia y mantenimiento de relaciones de interacción socioespacial será utilizada por los capitales inmobiliarios que desean renovar el segmento de demanda que habitualmente constituye su demanda solvente. Para atraer nuevamente al mercado la misma demanda, los capitales deben superar la barrera del tiempo de la depreciación física de las edificaciones.

La forma de realizar esta operación es la misma que utilizan otros sectores de bienes de consumo duradero, esto es, promover continuamente la diferenciación de productos, de tal manera que se dé una depreciación ficticia de los bienes de consumo duradero. Esta devaluación ficticia de una parte del stock suscita un mercado secundario que será determinante en el mantenimiento de la liquidez del mercado de inmuebles nuevos. Es decir, la depreciación debe darse de tal forma que los in- 
muebles tengan aún vida útil y, sobre todo, representen una opción de vivienda para estratos sociales inferiores a los que residían anteriormente en esa espacialidad. Pero en el caso del mercado inmobiliario se dan dos dificultades para la utilización de esta práctica empresarial. La primera, respecto a la inmovilidad espacial de los bienes. Así, la depreciación ficticia significa un desplazamiento espacial del vector de actuación de los capitales inmobiliarios y una imposibilidad de eliminación del mercado de los bienes depreciados de forma ficticia. El último problema fue resuelto con el mercado secundario, donde la franja temporal de sus productos es superior a los dos otros mercados secundarios de bienes de consumo duradero (automóviles, electrodomésticos, etcétera). La existencia del mercado secundario, inclusive, reduce los problemas relacionados a los altos valores individuales, pues la mayor parte de las transacciones en el mercado formal son contratos casados, donde el eventual comprador de un inmueble debe vender, o vendió otro inmueble. En otras palabras, la mayor parte de los compradores de bienes inmobiliarios también son (o fueron) vendedores en el mercado secundario.

Este hecho introduce una dificultad para las estrategias capitalistas de diferenciación de los productos inmobiliarios, pues una desvalorización desmedida (depreciación ficticia) del stock residencial existente puede reducir la liquidez del mercado primario e inviabilizar la operación de diferenciación del producto inmobiliario. Así, los capitalistas inmobiliarios, en sus estrategias de uso del suelo formal, deben procurar desvalorizar el stock para algunos (aquellos que buscan atraer como demanda solvente), pero esa desvalorización debe representar una valorización para quienes garanticen la liquidez del mercado primario, o sea, para los sectores inmediatamente inferiores en la jerarquía de estratificación social. De este modo, toda desvalorización ficticia del stock promovida por la diferenciación del producto y/o espacial es una depreciación relativa, pues también representa una posibilidad de valorización locacional e inmobiliaria para otros estratos sociales.

Como este efecto está encadenado hacia atrás, pues quien compra siempre vende, la operación de diferenciar los productos inmobiliarios se transforma en una cadena urbana de desvalorizaciones-valorizaciones inmobiliarias, donde la actuación del capital en un pequeño segmento del mercado puede promover una modificación más amplia en la cartografía socioespacial (Abramo, 2011).

Desde el punto de vista del movimiento socioespacial existen dos elementos críticos importantes. El primero es una diferenciación del producto, que envuelve, necesariamente, un desplazamiento espacial de la oferta: ofrecer un producto diferente en una espacialidad diferente. Y aquí ocurre el surgimiento del segundo elemento crítico, pues cuando los capitalistas inmobiliarios pretenden trasladarse espacialmente, su oferta debe desplazar a una parte de las familias que desean disfrutar de la externalidad de vecindad (estar entre los suyos y ser/tener una distinción socioespacial en relación con los otros). Así, una depreciación ficticia del stock inmobiliario, una diferenciación de la oferta en relación al stock existente, también exige un traslado de una externalidad de vecindad. En este sentido, toda operación 
de destrucción ficticia de una parte del stock inmobiliario, al tener que recrear una externalidad de vecindad, es, de hecho, una innovación espacial. Y esta renovación, aunque procura correr solamente una pequeña parcela de la demanda, envuelve una serie de desplazamientos domiciliares en cascada, con el necesario movimiento espacial de la externalidad de vecindad, como puede verse en el siguiente gráfico.

\section{GRÁFICO 2 | Estratificación socioespacial del mercado formal de viviendas y lógica de los desplazamientos en cascada}

DESPLAZAMIENTO ESPACIAL DE LA ESTRATIFICACIÓN SOCIAL
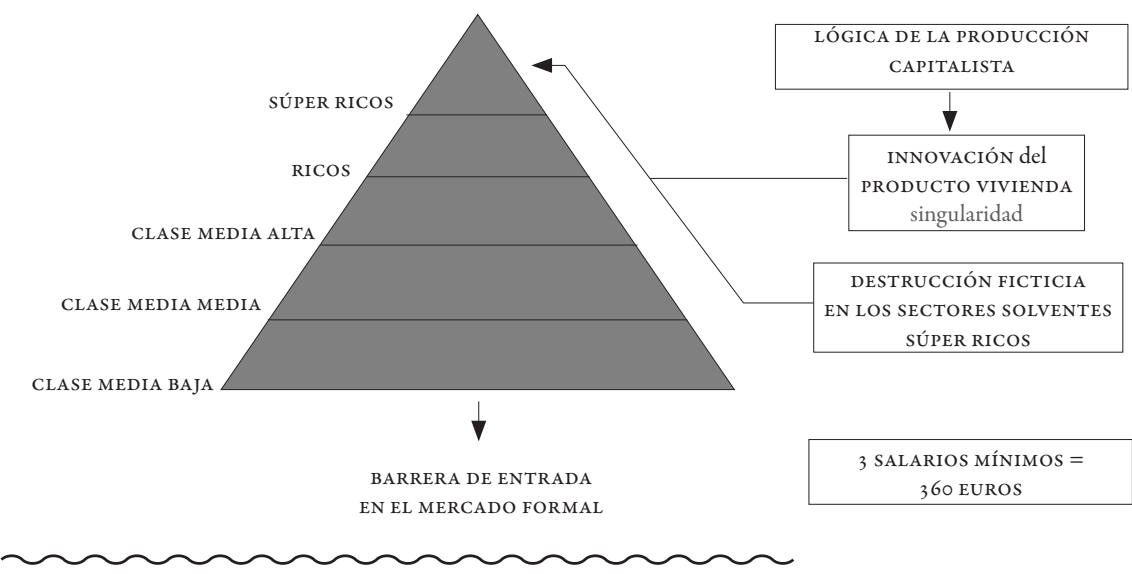

PRODUCCIÓN DE LA CIUDAD FORMAL: ESTRUCTURA SOCIOESPACIAL

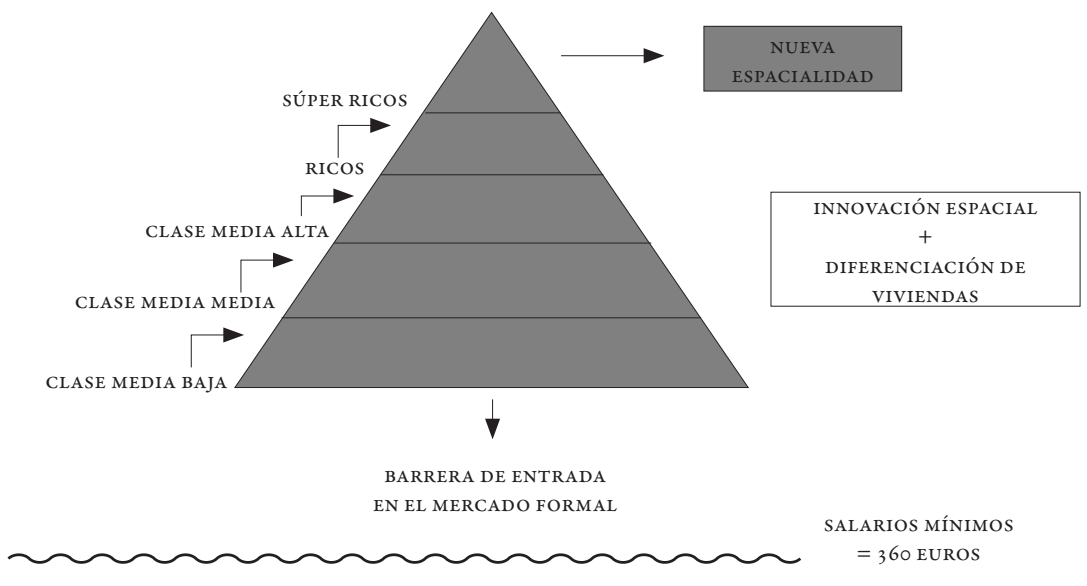

FUENTE ELABORACIÓN PROPIA. 
El efecto urbano de este movimiento de desplazamientos domiciliares y de externalidades de vecindad, promovido por una pequeña intervención de diferenciación del producto para un segmento restrictivo del mercado, se asemeja a un caleidoscopio, donde el mínimo desplazamiento de un cristal reconfigura toda la imagen. Así, podemos afirmar que el funcionamiento del mercado formal tiene una dinámica caleidoscópica, donde la acción localizada de algunos capitales puede generar una serie de efectos correlativos en cascada, y en la mayor parte de los casos desde lo alto de la pirámide social hacia abajo (Abramo, 2011).

El lector debe preguntarse la razón de esta digresión, dado que este trabajo tiene como propósito discutir la producción de la forma espacial de las ciudades latinoamericanas. La razón está relacionada con el acto generador del movimiento caleidoscópico de las mudanzas de uso del suelo urbano formal. El acto que promueve el movimiento caleidoscópico es una innovación espacial. Como sostuvimos anteriormente, este reordenamiento espacial es la articulación de un nuevo producto en una nueva espacialidad urbana. No obstante, trasladar espacialmente una demanda también impone un desplazamiento de la convención urbana (la externalidad de vecindad). Solo se puede identificar una innovación espacial, promovida por los capitales inmobiliarios, cuando se tiene esos dos componentes asociados. En general, la posibilidad de articular los dos elementos se vincula a una operación de cierta escala en relación con el uso del suelo urbano. La escala de la operación es importante, pues exige la actuación de varios capitales inmobiliarios y, por lo tanto, alguna forma de coordinación de la misma. Así, esta innovación devela, en términos espaciales, una de las paradojas del funcionamiento del mercado — su carácter competitivo y de decisiones individuales y autónomas- y, además, exige alguna coordinación para materializar el resultado anticipado: innovación del producto y/o hábitat con un desplazamiento espacial de la externalidad de vecindad. Este doble movimiento revela el ambiente de incertidumbre urbana en el cual se toman las decisiones locacionales (de los capitales y de las familias) (Abramo, 2011).

Una forma de disminuir la incertidumbre en relación con las innovaciones espaciales es promoverlas con una estrategia locacional de contigüidad espacial. Así, es posible sugerir que, en las últimas décadas, las innovaciones espaciales en las grandes ciudades latinoamericanas se manifestaron a partir de un proceso de extensión de la ciudad formal, a través de su continua promoción entre los estratos superiores de la pirámide de la distribución de la renta. En términos de la estructura urbana, esta estrategia de actuación de los capitales inmobiliarios es promotora de una ciudad de estructura difusa. Una ilustración de tal tendencia es la evolución del uso del suelo del sector más rico de la ciudad de Río de Janeiro, donde este segmento de demanda solvente es sistemáticamente desplazado espacialmente, promoviendo una dinámica de extensión de la ciudad formal (ciudad difusa).

No obstante, el proceso de innovación espacial, promotor de la estructura formal difusa, tiene en su reverso un proceso de compactación de la estructura de uso formal del suelo. En este sentido, pueden identificarse los efectos de compactación 
asociados a las estrategias de innovación espacial. El primero remite al stock depreciado de forma ficticia por una innovación espacial, al ser ocupado por familias de un estrato de ingresos bajos. En general, ese movimiento de sustitución domiciliar produce un efecto de crecimiento de la densidad habitacional, pues, a precios de suelo superiores, las familias tienden a consumir menos espacio urbano, y su conclusión sería optar por unidades habitacionales menores a las que dejaron. Así, las familias tenderían a sustituir el espacio domiciliar por una mejor accesibilidad y/o un movimiento ascendente en la jerarquía de representación socioespacial de la ciudad (Abramo, 2011).

MAPA 4 | Desplazamiento urbano de las innovaciones espaciales en la ciudad de Río de Janeiro

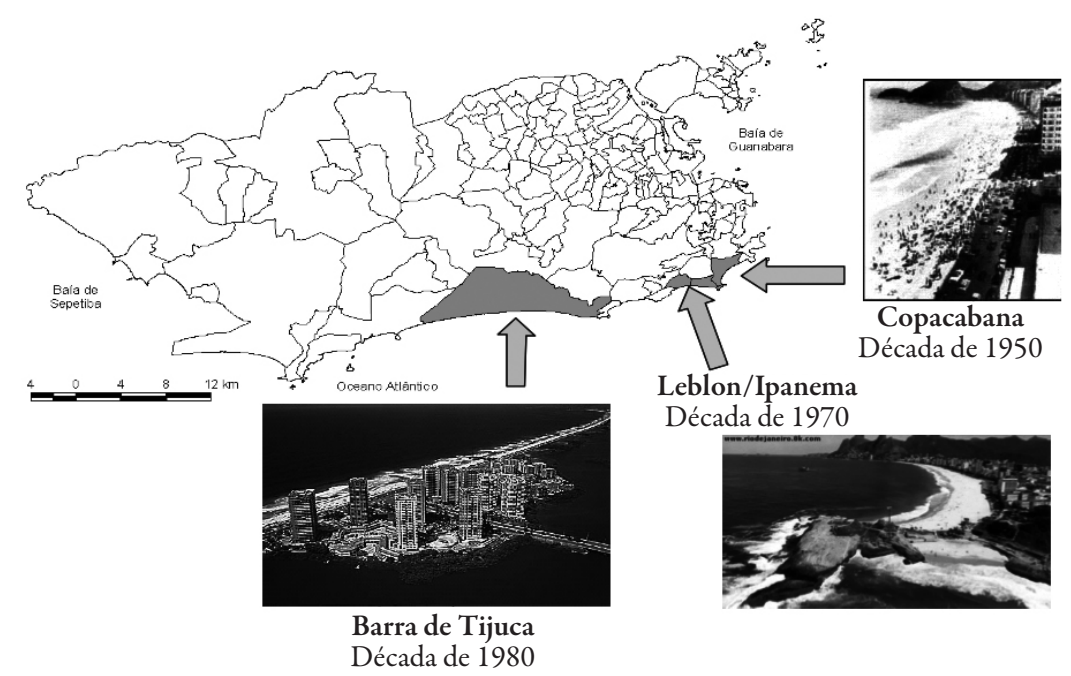

FUENTE ELABORACIÓN PROPIA.

El incremento de la densidad domiciliar también va acompañado de un aumento de la densidad predial en función de los lotes remanentes en esa localización urbana, teniendo ahora una lógica de uso del suelo más intensivo. La oferta de inmuebles nuevos se adapta a la demanda potencial de un estrato de renta familiar inferior, sin necesariamente reducir los precios del suelo. Así, el ajuste será ofrecer unidades habitacionales con un tamaño medio inferior al del stock existente, produciendo un crecimiento de la densidad predial. Como ya se señaló, este proceso de sustitución no se restringe a una única localización, sino que se replica en un conjunto de zonas urbanas, y por las mismas razones. O sea, para que una familia adquiera un nuevo inmueble, debe vender otro. Ese inmueble tiende a ser adquirido por una familia de estrato inmediatamente inferior de renta, y así se repite el proceso de compactación descrito. 
El resultado del efecto en cascada de esa dinámica de sustitución del consumo de espacio domiciliar por un mejor posicionamiento en la jerarquía de accesibilidades y/o socioespacial y de crecimiento en la intensidad del uso del suelo, que se inicia en los estratos más altos de renta y se transborda hacia los estratos más bajos, es un amplio proceso de compactación de la estructura del uso del suelo de la ciudad formal.

El segundo efecto de compactación remite a las estrategias de imitación que toda innovación exitosa tiende a generar en el comportamiento de la oferta capitalista. En este sentido, una innovación espacial que efectivamente promueve una desvalorización ficticia del stock y desplaza espacialmente una externalidad de vecindad tiende a ser imitada por otros capitales inmobiliarios. Pero el proceso económico de imitación de la innovación exitosa debe ser replicado para familias de estratos de renta inferiores, pues solamente así la imitación adquiere el carácter de una innovación relativa. La utilización de una innovación que fue concebida para estratos superiores de renta debe ser redefinida para una demanda de estratos inferiores y, sobre todo, rentabilizar el uso del suelo con un uso más intensivo. En otras palabras, la imitación, al inducir el uso más intensivo del suelo, promueve una compactación de la estructura urbana formal. En el Mapa 5, de la ciudad de Río de Janeiro, se observa que la difusión/imitación de una innovación tiende a dirigirse hacia varios vectores de vertebración de la ciudad.

El resultado agregado de la dinámica de valorización inmobiliaria será un doble proceso espacial. Por un lado, la innovación espacial busca una diferenciación del stock inmobiliario, pero su éxito induce al mimetismo y la reproducción de la innovación espacial en otras localizaciones urbanas, produciendo el efecto contrario, o sea, una homogeneización del stock residencial. Por otro lado, la innovación espacial se realiza promoviendo una estructura difusa de ciudad, pero los desplazamientos espaciales de las externalidades de vecindad y el proceso de imitación de esta innovación producen, justamente, lo opuesto: una estructura urbana compacta.

De hecho, la imitación de una innovación espacial promueve una tendencia de homogeneización del stock residencial, que obliga a los capitales inmobiliarios a introducir productos diferenciados. Así, en cuanto las innovaciones promueven una diferenciación del stock residencial, su imitación reafirma una tendencia contraria de homogeneización del mismo. La innovación genera una forma urbana difusa, en cuanto la imitación produce una estructura compacta. Otra vez, pero ahora para la territorialidad formal de la ciudad, puede verse que el funcionamiento del mercado origina una estructura urbana con una forma de uso del suelo com-fusa.

Así como existe una lógica de retroalimentación en la estructura com-fusa del uso del suelo informal, también en el mercado formal se da un circuito de funcionamiento que promueve la retroalimentación en su estructura compacta y difusa. En términos esquemáticos, la dinámica del mercado formal produce un proceso de polaridades que se refuerzan mutuamente: la diferenciación promueve la homogeneización que estimula la diferenciación. Como puede verse en el Diagrama 3, el resultado espacial del funcionamiento de ese mercado es una estructura de uso intensivo y extensivo del suelo, que crea, desde el punto de vista de la estructura urbana, una ciudad formal com-fusa. 
MAPA 5 | El mimetismo de las innovaciones espaciales en Río de Janeiro

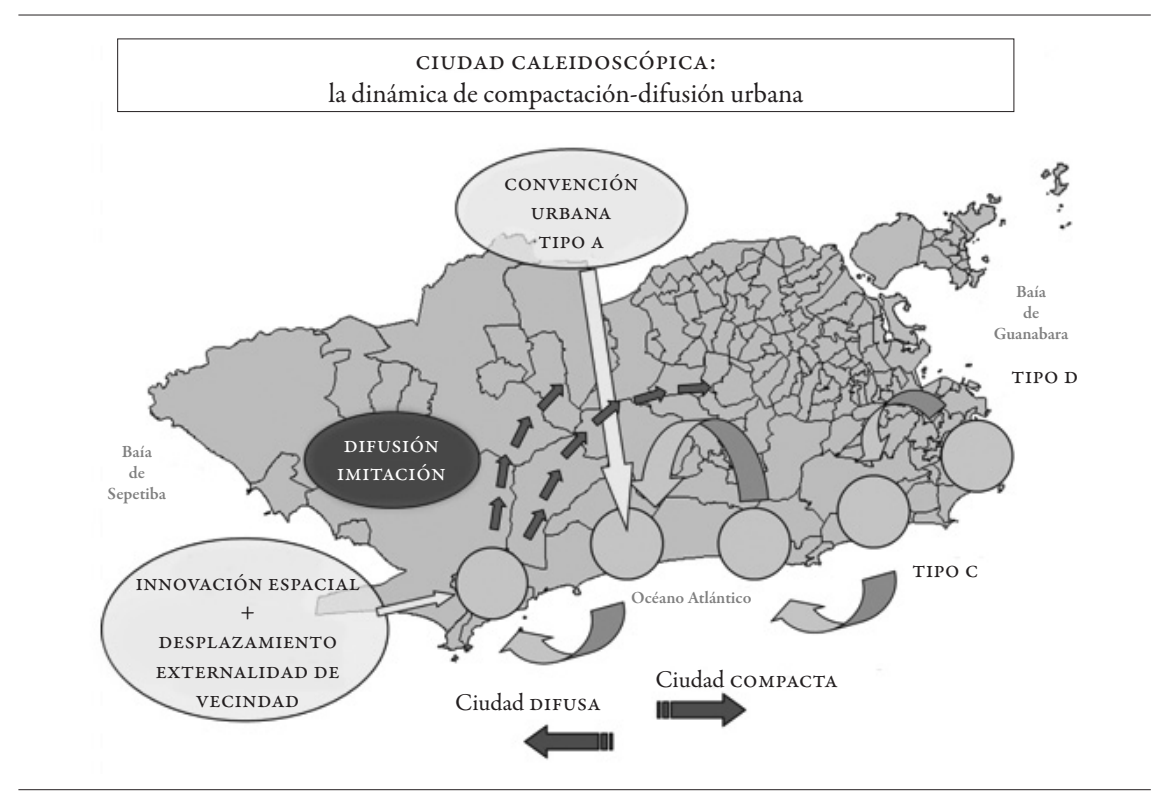

FUENTE ELABORACIÓN PROPIA.

DIAGRAMA 3 | Innovaciones espaciales y stock inmobiliario

INNOVACIONES ESPACIALES URBANAS Y STOCK

Diferenciación del producto inmobiliario

$+$

Proposición de desplazamiento de la externalidad de vecindad (convención urbana)

Diferenciación del stock inmobiliario

Difusión de la innovación $\longrightarrow$ Uniformización del stock

Trayectoria temporal de las innovaciones (permanencia)
DOBLE PROCESO

DIFERENCIACIÓN/UNIFORMIZACIÓN 
Concluimos con la propuesta de una lectura del funcionamiento del mercado formal según la cual los efectos de retroalimentación de las estrategias de los capitales inmobiliarios y de la demanda residencial generan la producción y la reproducción de una forma com-fusa de uso del suelo formal. Además, el circuito de producción de la estructura com-fusa formal se alimenta del mismo, caracterizando un sistema cerrado, que se aproxima a los sistemas de autoorganización mercantil.

\section{Conclusión}

La conclusión de este análisis sobre la relación entre el funcionamiento del mercado de suelo y la producción y reproducción de la estructura del uso del suelo pretende alertar sobre los riesgos del retorno del mercado como principal mecanismo de coordinación colectiva del uso del suelo urbano.

Como se observa en el Diagrama 4, tanto el mercado informal como el formal promueven un doble movimiento de compactación y difusión, lo que produce un uso del suelo de estructura com-fusa, en las grandes ciudades latinoamericanas.

\section{DIAGRAMA 4 | Estructura com-fusa de las ciudades latinoamericanas}

\section{Mercados formal-informal de suelo y la ciudad COM-FUSA}

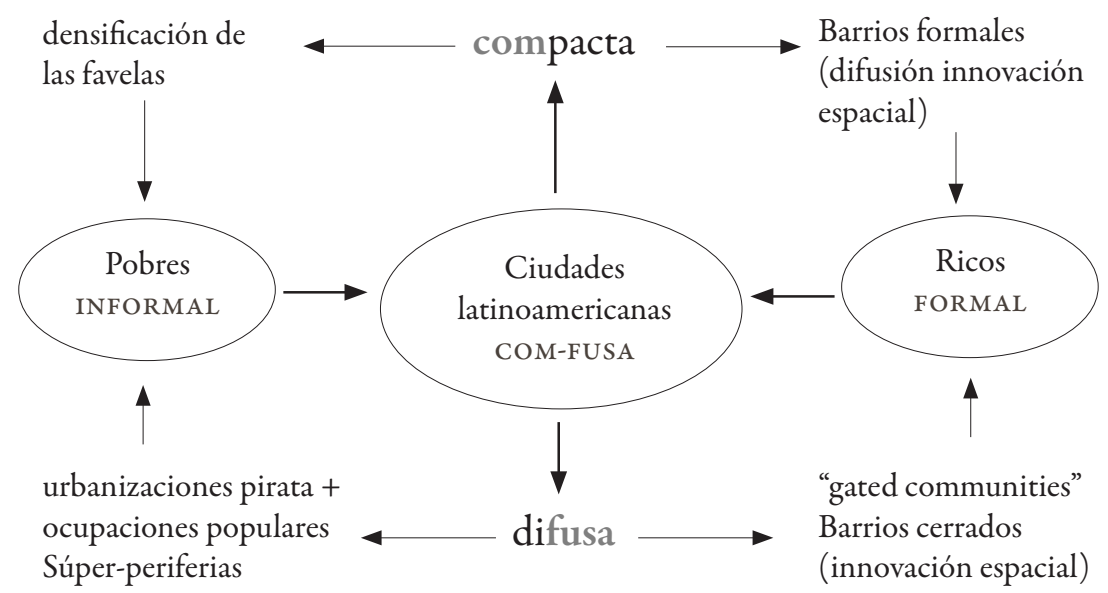

FUENTE ELABORACIÓN PROPIA.

No hay duda de que en una urbe con una forma com-fusa de uso del suelo, las exigencias de coordinación y de control público de la libertad de mercado son imprescindibles para construir una ciudad más igualitaria y más justa desde el punto 
de vista del acceso y la distribución de la riqueza urbana. Contra el regreso de la mano invisible del mercado, procuramos demostrar la imperiosa necesidad de luchar por el retorno de la acción pública de coordinación del uso del suelo urbano. Esta intervención pública debe ser renovada en sus decisiones por una amplia participación popular, a la vez que requiere superar la fórmula del planeamiento urbano modernista, donde el principio de la racionalidad instrumental delega a pocos las decisiones sobre la vida urbana de todos.

Podríamos concluir con una discusión sobre los impactos de la estructura comfusa de las ciudades latinoamericanas en la formulación de las políticas urbanas; sin embargo, decidimos terminar este trabajo reproduciendo una oportuna frase de Samuel Jaramillo (2008), en la que subraya la necesidad de un timón para controlar la furia de la mano inexorable del mercado. Según Jaramillo, "para orientarse en este mar embravecido de la ciudad caleidoscópica (com-fusa) no vale encomendarse al auxilio hipotético de alguna mano invisible caritativa (el mercado): son necesarios timón y brújula, es decir, se requiere de la acción política democrática, de nuevo de la planificación, y de la comprensión en conjunto de la dinámica urbana”.

\section{Referencias bibliográficas}

Abramo, P. (Ed.). (2003a). A cidade da informalidade. O desafio das cidades latino-americanas. Río de Janeiro: Ed. Sette Letras.

Abramo, P. (2003b). A dinâmica do mercado imobiliário e a mobilidade residencial nas favelas do Rio de Janeiro: resultados preliminares. [Informe de investigación]. Río de Janeiro: Instituto de Planeación Urbana y Regional (IPPUR) de la Universidad Federal de Río de Janeiro (UFRJ).

Abramo, P. (2005). A exuberância econômica nas favelas: um estudo das atividades econômicas e imobiliárias na favela do Jacarezinho, Rio de Janeiro. [Informe de investigación]. Río de Janeiro: Observatório Imobiliário e de Políticas do Solo (Oipsolo)/Instituto de Planeación Urbana y Regional (IPPUR) de la Universidad Federal de Río de Janeiro (UFRJ)/Instituto Municipal de Urbanismo Pereira Passos (IPP)-Prefeitura da Cidade do Rio de Janeiro.

Abramo, P. (2006a). Caracteristicas estruturais do funcionamento do mercado informal de solo nos assentamentos informais consolidados das grandes cidades brasileiras. Río de Janeiro: Habitare/Finep.

Abramo, P. (2006b). Características estruturais do mercado informal de solo nas grandes metrópoles latino-americanas. [Informe de investigación]. Cambridge, MA: Lincoln Institute of Land Policy.

Abramo, P. (2009). Mercado e favela: a nova porta de entrada dos pobres nas cidades brasileiras. Porto Alegre: Habitare-Finep-Antac.

Abramo, P. (2010a). Mercado e ordem urbana. Do caos a teoria da localização residencial. Bogotá: Ed. Universidad Externado.

Abramo, P. (2010b). Mercado informal e impacto das politicas públicas nas favelas do Rio de Janeiro. [Relatório de Pesquisa]. Río de Janeiro: Observatório Imobiliário e de Políticas do Solo (Oipsolo)/Fundação Carlos Chagas Filho de Amparo à Pesquisa do Estado do Rio de Janeiro (Faperj), 2010. 
Abramo, P. (2011). A cidade caleidoscópica. Bogotá: Ed. Universidad Externado.

Abramo, P. (2012). A teoria econômica da favela. Río de Janeiro: Observatório Imobiliário e de Políticas do Solo (Oipsolo)/Universidad Federal de Río de Janeiro (UFRJ) (en prensa)

Agamben, G. (2004). Estado de Exceção. São Paulo: Boitempo.

Alegría, T. (2005): Legalizando la ciudad. Asentamientos informales y procesos de regularización en Tijuana. Tijuana: Colegio de La Frontera.

Azuela, A. (1989). La ciudad, la propiedad y el derecho. México: Colegio de México.

Azuela, A. (2001). Definiciones de informalidad. Cambridge, MA: Lincoln Institute of Land Policy.

Bagnasco, A. (1999). Tracce di comunita. Boloña: Il Mulino.

Bourdieu, P. (Ed.) (1994). La misére du monde. París: Seuil.

Bruni, L. (2006). Reciprocitá. Dinamiche di cooperazione economia e societá civile. Milán: Bruno Mondadori.

Caillé, A. (2000). Lantropologie du don. París: Desclée de Bouwer.

Coriat, B. \& Saboia, J. (1989). Regime de acumulação e relação salarial no Brasil: um processo de fordização forçada e contrariada. Ensaios FEE (Porto Alegre), 9(2), 3-45.

Fernandes, E. (2003). Perspectivas para a renovação das políticas de legalização de favelas no Brasil. En P. Abramo (Ed.), A cidade da informalidade. $O$ desafio das cidades latino-americanas (pp. 139-172). Río de Janeiro: Sette Letras.

Jaramillo, S. (2001). Experiencia colombiana en la recuperación estatal de los incrementos del precio del suelo. La contribución de valorización y la participación en plusvalías. En M. Smolka \& F. Furtado (Eds.), Recuperación de plusvalías en América Latina: alternativas para el desarrollo urbano (pp. 71-98). Santiago de Chile: Instituto de Posgrado e Investigación, Pontificia Universidad Católica de Chile/Lincoln Institute of Land Policy.

Jaramillo, S. (2008). Reseña del libro Cidade caleidoscópica, de Pedro Abramo. Revista Territorios, n. ${ }^{\circ}$ 18/19: Mercados inmobiliarios populares (Bogotá: Asociación Colombiana de Investigadores Urbano Regionales, ACIUR).

Lipietz, A. (1991). Audácia: uma alternativa para o século XXI. São Paulo: Nobel.

Maldonado, M. M. (2005). La plusvalía en beneficio de los pobres: el Proyecto Usme en Bogotá, Colombia. Land Lines, 15(2). Cambridge, MA: Lincoln Institute of Land Policy.

Maricato, E. (2001). Brasil, cidades: alternativas para a crise urbana. Petrópolis: Vozes.

Moulaert, F., Rodriguez, A. \& Swyngedouw, E. (2003). The globalized city. Economic restructing and social polarization in European cities. Oxford: Oxford University Press.

Pelligia, V. (2007). Il paradossi della fiducia. Scelte razionali e dinamiche interpersonali. Boloña: Il Mulino.

Rallet, A. \& A. Torre (Eds.) (2007). Quelle proximité pour innover? París: Harmattan.

Rodríguez, A. \& Sugranyes, A. (2005). Los con techo. Un desafio para la politica de vivienda social. Santiago de Chile: Ediciones SUR.

Rolnik, R. (1999). Exclusão territorial e violência. São Paulo em Perspectiva, 13(4), 100-111.

Sabatini, F. (2003). La segregación social del espacio en las ciudades de América Latina. Serie Azul, n. 35. Santiago de Chile: Pontificia Universidad Católica de Chile.

Sabatini, F. (2005). Relación entre promoción inmobiliaria y segregación residencial: giros insospechados de la ciudad. Cambridge, MA: Lincoln Institute of Land Policy.

Sugai, M. I. (2007). Há favelas e pobreza na "Ilha da Magia"? Favela e mercado informal: a nova porta 
de entrada dos pobres nas cidades brasileiras. Río de Janeiro: Fundação Carlos Chagas Filho de Amparo à Pesquisa do Estado do Rio de Janeiro (Faperj)/Financiadora de Estudos e Projetos (Finep).

Taylor, C. (2002). El multiculturalismo y la politica del reconocimiento. Madrid: Fondo de Cultura Económica de España.

Vetter, D. \& Massena, R. (1981). Quem se apropria dos benefícios líquidos dos investimentos do Estado em infra-estrutura? En L. Machado (Ed.), Solo urbano. Tópicos sobre o uso da terra (pp. 49-78). Río de Janeiro: Zahar.

Williamson, O. (1985). The economic institutions of capitalism. New York: The Free Press. 
